\title{
DUCTILITY OF PRESTRESSED CONCRETE MEMBERS
}

\author{
R. W. G. Blakeley* and R. Park**
}

\section{Summary}

An analytical determination of the momentcurvature relationships of prestressed concrete members under high intensity monotonic loading is presented, and compared with experimental results. The effects on ductility of such variables as transverse reinforcement, distribution of the prestressing steel within the section, steel area ratio, and axial load are described. A comparison is made of the ductility available in comparable prestressed and reinforced concrete members. The results of tests on prestressed concrete beam-column assemblies under high intensity cyclic loading are referred to and conclusions are drawn on the seismic resistance of prestressed concrete members. Load factors for seismic design are discussed.

\section{Introduction}

The use of prestressed concrete for primary seismic resistant elements has been a subject of some controversy. A survey of the background to this controversy and the current philosophy of seismic design of prestressed concrete has been previously published. While some investigators ${ }^{2}$ have expressed confidence in the ability of certain types of prestressed concrete structures designed using a conventional code approach to withstand strong earth quakes, design engineers have generally been cautious in their use of the material for seismic resistance. The principal reasons for caution have been an acknowledgement of the greater elastic recovery and hence lower energy dissipation characteristics of prestressed. concrete relative to reinforced concrete, and a fear that prestressed concrete is a brittle material without significant post elastic ductility being available.

The moment-curvature relations for prestressed concrete under monotonic and cyclic loading hold the key to an understanding of ductility and energy dissipation respectively. This paper presents the results of an analytical study of the behaviour of prestressed concrete under monotonic loading, and the effect of a number of practical section variables on ductility are discussed. The results of an experimental investigation into the behaviour of prestressed concrete members under high intensity cyclic loading are referred to, but are more fully reported elsewhere

It is sometimes argued that the response of a prestressed concrete structure to a severe

* Graduate Student, University of Canterbury.

* Professor of Civil Engineering, University of Canterbury. earthquake will be greater than that of a comparable reinforced concrete structure, because of the smaller energy dissipation capacity and lower percentage critical viscous damping. This could mean that the use of higher load factors for seismic design of prestressed concrete structures are warranted, or alternatively, that more ductile sections are required. The subject of load factors for prestressed concrete is reviewed in the light of the results of this study.

\section{Theory for Monotonic Loading Analysis}

\subsection{Assumptions}

The following assumptions will be made:

(i) Plane sections remain plane after flexure.

(ii) The stress-strain relationship for concrete in compression is represented by the expression developed by Kent and Park ${ }^{4}$. The relationship is illustrated in Fig. 1. There are three regions as follows:

Region OA: $\quad \varepsilon_{c} \leqslant \varepsilon_{0}$
$f_{c}=f_{c}\left[\frac{2 \varepsilon_{c}}{\varepsilon_{o}}-\left(\frac{\varepsilon_{c}}{\varepsilon_{0}}\right)\right]$

Region $A B: \quad \varepsilon_{0} \leqslant \varepsilon_{c} \leqslant \varepsilon_{20 c}$

$f_{c}=f_{c}\left\{1-z\left(\varepsilon_{c}-\varepsilon_{o}\right)\right\}$

where $z=\frac{0.5}{\varepsilon_{50 h}+\varepsilon_{50 u}-\varepsilon_{0}}$

and $\varepsilon_{50 u}=\frac{3+0.002 f: c}{f i-1000}$

and $\varepsilon_{50 h}=\frac{3}{4} p^{n} \sqrt{\frac{b^{n}}{s}}$

where $\mathrm{p}^{\text {w }}=$ binding steel ratio, $b^{\text {winimum }}$ dimension of confined core, and $s=$ spacing of transverse reinforcement.

Region $B C: \quad \varepsilon_{20 c} \leqslant \varepsilon_{c}$

$f_{c}=0.2 f_{c}$

This relationship allows for a variation in slope of the falling branch section of the stress-strain curve according to the concrete strength and the degree of confinement. 
146

(iii) The maximum tensile strength of the concrete is assumed to be given by the expression:

$f_{t}^{\prime}=7.5 \sqrt{f_{c}} \quad$ p.s.i.

The stress-strain relationship in tension is assumed to follow the slope of the parabola of Region OA at the origin, and is given by,

$f_{c}=\frac{2 f i}{\varepsilon_{0}} \varepsilon_{c}$

(iv) The stress-strain relation for the prestressing steel is assumed to be of a Iinear-hyperbolic curve-linear" form as is illustrated in Fig. 2. The three regions which comprise the stress-strain relationship are expressed by:

$\varepsilon_{s} \leqslant \varepsilon_{s a} \quad f_{s}=\varepsilon_{s} E_{s}$, where $E_{s}=\frac{f_{s a}}{\varepsilon_{s a}}$

$$
\begin{aligned}
\varepsilon_{s a} \leqslant \varepsilon_{s} \leqslant \varepsilon_{s b} \quad f_{s}= & \frac{f_{s b} \varepsilon_{s b}-f_{s a} \varepsilon_{s a}}{\varepsilon_{s b}-\varepsilon_{s a}}+ \\
& \frac{\varepsilon_{s a} \varepsilon_{s b}\left(f_{s a}-f_{s b}\right)}{\varepsilon_{s}\left(\varepsilon_{s b}-\varepsilon_{s a}\right)}
\end{aligned}
$$

$\varepsilon_{s b} \leqslant \varepsilon_{s} \quad f_{s}=f_{s b}+\frac{\varepsilon_{s}-\varepsilon_{s b}}{\varepsilon_{s u}-\varepsilon_{s b}}\left(f_{s u}-f_{s b}\right)$

The hyperbolic assumption for the curved part of the stress-strain relation fits closely to experimental curves from steel control specimens.

(v) It is assumed that all losses in prestress due to time dependent effects have occurred at the time of loading for which the theory is determined.

\subsection{Development of Moment-Curvature Relation- ship}

The theory enables moment-curvature relationships to be computed for sections with general dimensions, with or without axial load, and with the prestressing tendons distributed into up to five positions down the section. The moment-curvature relationship is obtained in three successive stages depending upon the position of the neutral axis, as illustrated in Fig. 3. For the purpose of a general illustration an eccentric prestressing force is assumed. It is to be noted that the curvature is given by the angle $\phi$ in the fingure.

\section{2 .1 Stage 1}

When the section is subjected to prestress. ing force only it will have a negative (hogging) curvature if the prestressing force has a downward eccentricity。 The initial curvature may be calculated directly from the initial strain profile. If an increasing external positive moment is applied to the section the neutral axis will move upwards out of the section.

\section{2 .2 Stage 2}

During this stage the whole section is under compression, and the neutral axis lies below the section.

The total compressive force in the concrete is given by,

$C=\int_{0}^{1} f_{c} b D \cdot d y$

where $f$ is the stress in the concrete fibre at a distance yD from the top.

During this stage the surface concrete strain is less than $\varepsilon_{0}$ and $f_{c}$ may be represented by equation (1)

The steel strain at each tendon may be found from the initial steel strain due to prestress and the concrete strain at the level of the steel. The steel stresses are calculated from equation (9) as the steel strains are in the elastic range during this stage. By summation of the individual tendon forces the total tensile force, $T_{S}$, is calculated.

From equilibrium of forces on the section,

$C=T_{S}+P$

where $P$ is the external axial load ( $P=0$ in the case of a beam). The substitution for C and $T_{S}$ into equation (13) leads to a quadratic equation, from which the curvature corresponding to any value of neutral axis depth may be obtained. The corresponding moment can then be calculated.

Values of curvature and moment were determined for successively reducing values of neutral axis depth below the section.

\section{2 .3 stage 3}

The neutral axis lies within the section during this stage. The bottom fibres are under tension and cracks form at strains beyond the limiting tensile strain. The compressive force in the concrete is given by:

$c=-\int_{k}^{o} f_{c} b D \cdot d y$

where $f$ is represented by equations (1), (2) and $(6)^{\mathrm{C}}$

Divergent opinions are held on the effectiveness of the cover concrete at large strains, and to study this effect three analytical models for the stress-strain relationship of the cover concrete were developed:

(a) Model 1. The cover concrete follows the same stress-strain relationship as the core concrete.

(b) Mode1 2. The cover concrete follows the same stress strain relationship as the core concrete up to a strain of 0.004 . Any cover concrete at a strain greater than 0.004 is 
considered to have spalled and to have become ineffective.

(c) Model 3. The cover concrete can follow a separatestress-strain relationship from the core concrete at strains greater than $\varepsilon_{0}$. Hence allowance can be made for the different degrees of confinement between the cover and core concrete.

The tensile force in the concrete, $T_{C}$, depends on the existence of cracks. For the case where there are no cracks:

$T_{c}=\int_{k}^{1} f_{c} b D \cdot d y$

where $f_{c}$ is given by equation (8).

For the case where cracking has occurred:

$T_{c}=\int_{k}^{\gamma} r_{c} b D \cdot d y$

where $\mathcal{D}$ is the distance from the top fibre

to the top of the cracks.

The total tensile force in the steel, $T_{S}$, is determined from the stresses in the prestressing steel at each level. Stresses for particular strains are found from the appropriate equation (9) to (11).

From force equilibrium,

$C=T_{S}+T_{C}+P$

An iterative process was necessary for the solution of equation (17) because of the complex nature of the stress-strain relationships for the concrete and steel. For successive increments of surface concrete strain of 0.0001 the neutral axis depth was found and the corresponding curvatures and moments calculated.

\section{Analytical Study of Beams}

For beams $\varepsilon=0.002$ was assumed in equations (1), (2) and (3) as recommended by Kent and park ${ }^{4}$.

\subsection{Comparison of Theory and Experimental Results}

\subsubsection{Priestley's Tests}

Few experimental results have been publish. ed showing moment-curvature relations for prestressed concrete, and hence a comprehensive comparison of the theory with experimental results cannot be made. However, one wel1 documented series of tests which could be used was those of Priestley ${ }^{5}$. Seven beams with a 8 8 $x$ 4" cross section were tested simply supported over a span of 14'9". The beams were loaded by two point loads to give a constant moment zone over the central 6" of the span. Stirrups were included in the constant moment zone of only one of the beams and hence only in this case can a direct comparison be made with the authors theory for confined compression zones. Also, readings were not taken beyond the stage of crushing of the compression fibres. A comparison of
Priestley's and the authors" curves are shown in Fig。 4。 Priestley recorded experimentally both the average curvature over the length of the constant moment zone and the average of the maximum curvatures occurring at the tension crack positions within the constant moment zone. He also plotted moment-curvature relationships determined from his theory for both the curvature at a section which cracks in tension, (i.oe, the maximum curvature) and for the average curvature which takes into account changes in stress conditions between cracks. To standardize the curves, all values of the moment $M$ were divided by the theoretical "ultimate" moment $M_{u}$, and the curvatures $\phi$ were divided by the theoretical "ultimate" curvature at a crack $\phi_{u}$. The theoretical curves were calculated assuming an "ultimate" compressive strain in the concrete of 0.004 .

The theoretical approach used by the authors determined moments and curvatures at a section which cracks and hence corresponds to Priestley" $\mathrm{s}$ "maximum" experimental and theoretical curves. The Model 3 analytical curve with $\mathbb{Z}_{\text {cover }}=2 \times Z_{\text {core }}$ was chosen as providing the best representation of the concrete stress bI ock. This assumption will be discussed more fully later. Correlation with Priestley's theoretical curve was good and related well to the shape and "ultimate" conditions of the experimental curve.

It will be noted that there is a difference in the behaviour at cracking between theory and experiment. On the authors" theoretical curve there is a drop in load after cracking. Prior to flexural cracking, a tensile force is developed in the concrete at the bottom of the beam. When the beam cracks, the tension force in the prestressing steel must increase and for a prestressed concrete beam with a low steel percentage a considerable steel strain may be required to reach equilib. rium again. In the process a large crack height will be developed. During this stage there is a temporary reduction in moment resistance apparent on the theoretical curve.

If all the cracks in the constant moment zone of Priestley's beam had formed simultaneously, a drop of load would have been expected at cracking, because the deflection was held constant. As in fact the cracks did not appear simultaneously the exact load at which cracking was initiated was not discernible and does not appear on the experimental plot.

In this study the theoretical approach based on maximum curvature will be compared with experimental readings of average curvature from gauge lengths up to $12^{\text {". The }}$ justification for this may be seen in Fig. 4. The shape of the authors theoretical curve and the experimental "average" curve are very similar. The large difference between the average and maximum curvatures at a concrete strain of 0.004 in Priestley's test was because crushing occurred only above one or two cracks within the 6" length of the constant moment zone. However the much smaller gauge length used in the authors tests will cause a closer relationship between the average and maximum values. 


\subsubsection{The Authors Tests}

The investigation ${ }^{3}$ set out to examine experimentally the behaviour of prestressed concrete frames under seismic motions. Four full-scale precast prestressed concrete beamcolumn assemblies were tested under high intensity cyclic loading. Brief details of the test series are included in the Appendix.

Figure 5 illustrates the experimental beam plastic hinge moment-curvature relationships for Unit 2, and four theoretical moment-curvature curves. The experimental curves are for two particular cycles of load but the envelope oi them should be similar to the curve from monotonic loading. The theoretical curves show a greater initial stiffness than the experimental curve for the $12^{\text {m }}$ gauge length adjacent to the column face. This is because the theoretical curves do not take into account the smaller cross section at the $\frac{1}{2}$ recessed mortar joint at the column face. The reduced stiffness plus the lack of tensile strength across the mortar joint meant that the first crack occurred in the joint at a lower moment than that predicted. Far a further comparison, the experiinental moment-curvature relationship for the $8 "$ gauge length on the beam adjacent to the joint (but excluding the mortar joint) is also plotted in Fig. 5. The initial stiffness of this experimental curve corresponds exactly to the theoretical beam stiffness. However beyond the theoretical cracking moment the two curves diverge because the formation of a crack withil the $8^{\prime \prime}$ gauge length is retarded by the proximity of a wide crack in the mortar joint.

All three analytical models for the concrete stress block after maximum stress are compared with experiment in Fig. 5. Model 1, which allowed the cover concrete to follow the same stressmstrain relationship as the core concrete, closely approximated the maximum moment capacity, but made no allowance for reduction of moment with increasing curvature. Model 2, which considered all cover concrete at a strain greater than 0.004 to have spalled, underestimated the post-crushing moment resistarice of the section. Various values of $\mathrm{Z}$ for the cover concrete were tried in Model 3 and the curve which gave the best fit to the experimental results had a $Z$ value for the cover of 80 (i。e. approximately twice the $z$ value for the corel. Significant points on this moment-curvature plot are marked in Fig. 5. Also plotted in Fig. 5 for comparison is the curve for Model 3 with $Z$ for the cover as 500 , the value for unconfined concrete. The discontinuity in the theoretical curves represents the point of fracture of the tension steel at an assumed ultimate strain of 0.04 .

When comparing theory and experiment at high curvatures it should be noted that the experimental plot is for two particular cycles of load and there may have been slightly different characteristics if loading had been monotonic, especially as at the peak of cycle 4, on Fig. 5, both steel and concrete were behaving inelastically.

\subsection{Effect of Transverse Reinforcement on the Ductility of the Beams of Units 1 and}

The concrete stress block model which gave the best fit to the experimental curves for Unit 2 was ModeI 3 with $\mathrm{z}_{\text {cover }}=2 \times \mathrm{z}_{\text {core }}$.
However, for the more lightly stirrupped Unit 1, the best fit was obtained from Model 1 with $\mathrm{Z}_{\text {cover }}=\mathrm{Z}_{\text {core }}(=150)$. This result appears reasonable as intuitively one would expect that with a larger stirrup spacing the cover and core concrete would behave more monolithically. This difference in appropriate stress block model does restrict a general study of the effect of transverse reinforcement on ductility. However a valuable guide may be obtained from comparing the practical cases of Units 1 and 2 because Unit 1 contained only sufficient stirrups for shear, whereas Unit 2 contained additional stirrups for ductility. Fig. 6 illustrates the appropriate theoretical momentcurvature relationships for Units 1 and 2, plotted for the same value of concrete strength. Clearly the confined concrete of Unit 2 enables it to retain higher moments at large curvatures. However the curve for Unit 1 still shows adequate moment resistance, even at very high curvatures。

It is concluded that prestressed concrete beam sections with sufficient transverse rein. forcement to satisfy the shear requirements of codes may be extremely ductile.

\subsection{Effect of Distribution of Prestressing Steel in Member}

A topic of interest for the design engineer is the effect on the moment capacity of the distribution of prestressing tendons down the section. To make this comparison moment-curvature characteristics were computed for a section keeping the magnitude of the total prestressing force and its line of action constant but varying the numbers and positions of tendons. An axial line of action of the total prestressing force was chosen because this configuration provides the best resistance to seismic load reversals. The theoretical model developed for the Unit 2 beam was used for the concrete stress block.

The results are shown plotted in Fig. 7 . It is apparent that all curves are very similar apart from that for the single tendon position. In this case there is a lower maximum moment capacity and a substantial decline in moment resistance after maximum. The reason for the curve for two positions of the tendons being lower than those for three, four, or five positions was that the two tendons were not placed at the extremities of the section and hence this was a slightly less favourable configuration than the others. This was done to provide a comparison with the practical case of Unit 2. The sharp drop off in moment at high curvatures occurs when the tendons reach the fracture strain, $\varepsilon_{\text {su, in }}$ tension. At high curvatures the tendons in the compression zone may lose their tension and act as compression reinforcement. The same elastic properties in compression as in tension was assumed for these tendons since the compressive stress induced in the tendons was never very great.

It may be concluded that for seismic resistance of concentrically prestressed members it is advantageous to have more than one tendon position within the section, but there is Iittle difference in behaviour between sections with two or more positions of tendons for the same total prestressing force. 


\subsection{Effect of Variation of Steel Area Ratio}

In order to study the effect of varying the steel area ratio on the moment-curvature relationships, a model of the dimensions shown on Fig. 8 was chosen with eccentric prestressing at a steel depth of $0.8 \mathrm{D}$. A representative $\mathrm{z}$ value for the core of 80 was taken. Since this was intermediate between the case of Unit 2 (with $\mathrm{z}_{\text {core }}=38$ and $\left.\mathrm{z}_{\text {cover }}=2 \times \mathrm{z}_{\text {core }}\right)$, and that of Unit 1 (with $\mathbf{Z}_{\text {core }}=155$ and $\mathbf{Z}_{\text {cover }}$ $=\mathbf{z}_{\text {corel }}$, a value for $\mathbf{z}_{\text {cover of }} 1.5 \times \mathbf{z}_{\text {core was }}$ chosen. Curves for values of steel area ratio, $\mathrm{p}=\mathrm{A}_{\mathrm{S}} / \mathrm{bD}$, from 0.002 to 0.012 are plotted on Fig. 8. Note that $p$ will be defined as the steel content as a proportion of the total area of the cross section.

The general pattern of the curves shows an increase in moment capacity, but a decrease in ductility with increasing $\mathrm{p}$ 。

The limitation on steel percentage specified in ACI $318-63^{6}$ and included in the proposed revision? of the ACI $318-63$ is

$\frac{A_{s} f_{s p}}{b d f_{c}} \leqslant 0.30$

For the section studied, using the value for the steel stress at maximum moment, $f_{s p}$, calculated from the theory, equation (18) reqlires $\mathrm{p}=\mathrm{As}_{\mathrm{s}} / \mathrm{bD} \leqslant 0.00694$. The moment-curvature plot for this value of steel percentage is also shown in Fig. 8. The intention of the ACI equation is to prevent a brittle failure from over-reinforcement. It is apparent that the curve for $p=0.00694$ exhibits reasonable ductility but that for deismic design it may be necessary to restrict $p$ to a smaller value than that given by the ACI equation.

It is of interest to compare the calculated stress in the prestressing steel at maximum moment on the moment-curvature plot of the limiting steel ratio with the ACI code expression given for steel stress at ultimate load.

(i) From the theoretical moment-curvature plot:

At maximum moment $\left(\varepsilon_{c c}=0.00301\right)$, $f_{S}=211,200$ p.s.i.

(ii) From $\mathrm{ACI}_{n} 318.63^{6}$ and the proposed revision?:

$f_{s p}=f_{s u}\left(1-0.5^{\circ} \frac{A_{s}}{b d} \cdot \frac{f_{s u}}{f_{c}^{\circ}}\right)$

This expression gives $f_{s p}=204,000$ p.s.i.

The agreement is good and is even better at smaller steel contents.

When the steel ratio exceeds the limiting value, ACI $318-63^{6}$ and the explanation of the proposed revisions? specify that the ultimate moment to be taken is not greater than:

$\mathrm{M}_{\mathrm{u}}=\phi\left(0.25 \mathrm{f}: \mathrm{bd}^{2}\right)$
This moment corresponds in Fig。 8 to:

$100 \mathrm{M} /\left(\mathrm{f}_{\mathrm{c}}^{\mathrm{b}} \mathrm{bD} \mathrm{D}^{2}\right)=\varnothing \times 16.0=14.40$

Before application of the capacity reduction factor of $\phi=0.9$, the maximum moment allowed is very close to the maximum moment for limiting steel ratio.

It is concluded that the limit of steel percentage imposed by the ACI code 6 , 7 does in fact result in reasonable ductility but to ensure adequate ductility for seismic design it may be desirable to reduce the 0.3 on the right hand side of equation (18) to say 0.2. The value for $f_{s p}$ recommended by the ACI code 6 , ? results in a good approximation for the maximum moment.

\subsection{Comparison of Prestressed and Reinforced Concrete}

Because more is known about the seismic behaviour of reinforced concrete structures, attempts are often made to compare prestressed concrete with reinforced concrete. It is therefore of value to study the moment-curvature characteristics of the two materials. Fig. 9 illustrates moment-curvature responses for typical reinforced concrete sections as determined in an analytical study by Kent ${ }^{8}$, and for comparison typical prestressed concrete section responses. The same section geometry was used for both studies as shown in Fig. 9. The value of maximum concrete strength, $f:$, for the reinforced concrete study was 4008 p.s.i., and a representative value of $f_{i}=$ 6000 p.s.i. was chosen for the prestressed concrete members.

The analytical model which had been used for the reinforced concrete study considered all cover concrete at a strain greater than 0.004 to be ineffective. For consistency the same model was used for prestressed concrete. This model provides good correlation with experiment at low values of $Z$, but is slightly. conservative at high values of $z$. Curves for values of $\mathrm{Z}$ of 10 and 100 were plotted for both materials, thus presenting the extremes of the likely range of degree of confinement in such beams.

Rather than plot the curves to the dimensionless moment term, $M /\left(f^{\prime} b^{2}\right)$, the expression $\mathrm{M} / \mathrm{bd}^{2}$ was chosen as this allowed a direct comparison of prestressed and reinforced concrete members with the same maximum moment capacity (and hence same design moment for an ultimate strength approach). For example, P6 and $R 10$ have identical values of maximum moment from the expression, $M / b^{2}$. A study of their respective curves show that $P 6$ has a greater curvature at the crushing strain of 0.004 than does R10. The reasons for this may be seen from a comparison of section behaviour at crushing, as over: 


\begin{tabular}{|c|c|c|}
\hline & $\mathrm{P} 6$ & $\mathrm{R} 10$ \\
\hline $\mathrm{k}$ & 0.201 & 0.319 \\
$\mathrm{Qd}$ & 0.01989 & 0.01253 \\
$\mathrm{I}=\frac{f_{\mathrm{s}} \mathrm{A}_{\mathrm{S}}}{\mathrm{bd}}$ & 945 & 1000 \\
$\frac{\mathrm{M}}{\mathrm{bd}}$ & 0.910 & 0.859 \\
\hline
\end{tabular}

The curvature when the extreme concrete fibre strain is 0.004 is dependent on the neutral axis depth. This depth is in turn dependent on the compressive force and the concrete strength, $f_{c}$. Even though the values of compressive force are comparable in the two cases, the greater concrete strength for P6 allows a smaller neutral axis depth and therefore a larger curvature.

It is concluded that generally a prestressed concrete beam should have a greater curvam ture at crushing, than its reinforced concrete counterpart with the same maximum moment capacity.

It is of interest to compare the ductility factors as commoniy defined for prestressed and reinforced concrete. The rotational ductility factor for prestressed concrete is usually defined as the ratio of rotation over a small increment of length to rotation over that length at first cracking, whereas for reinforced concrete the rotational ductility factor is taken as the ratio of rotation over a small increment of length to rotation over that length at first yield of the tension steel. The rotational ductility factors at the crushing strain of 0.004 have been tabulated on Fig. 9 for all the curves plotted. The rotational ductility factor terms for the prestressed concrete members are up to 8 times those of the reinforced concrete members for the same values of curvature. This illustrates why it is not possible to relate the ductility factor requirements as commonly defined for prestressed concrete members to those already known for reinforced concrete members.

Rosenbleuth 9 has developed an equation to relate forces and deflections in two single degree systems, one with an elasto plastic hysteresis loop and the other with an elastic bilinear hysteresis 100 . The design acceleration spectrum is idealized as hyperbolic in the range of interest, and the two systems are assumed to have the same mass and the same initial stiffness, and a coefficient of damping not smaller than $2 \%$ for small oscillations. The details of the assumed. hysteresis loops are illustrated in Fig. 10. The expression derived is:

$\frac{F_{2}}{F_{1}}=\frac{\mu_{1}}{H_{2}}\left[\frac{1+2 \mu_{2}}{3 H_{2}}\right]^{0.6}$ where the ductility factors are:

$$
\begin{aligned}
& \mu_{1}=D_{1} K / F_{1} \\
& \mu_{2}=D_{2} K / F_{2}
\end{aligned}
$$

For a prestressed concrete member such as P6 in Fig. 9 the bilinear representation of its moment-curvature response would be more realistic if the value of moment corresponding to $\mathbb{F}_{2}$ was taken as the maximum moment rather than the moment at cracking. Hence if we compare P6 and R10 for which $F_{1}=F_{2}$ and substitute the ductility factor of $\mathbb{R} 10$ at crushing $\left(\mu_{1}=4.75\right)$ into equation (21), the required ductility factor for the prestressed member with the same initial slope as R10 and same yield curvature, would be 6.72. This corresponds to a curvature $\phi d$, on Fig. 9 of 0.0175 , which is less than the curvature at crushing for 96 . That is, the extra ductility demand for the prestressed concrete model is more than compensated for by the extra ductility available。

Alternatively one may consider members with the same ductility demands such as $\mathrm{P} 4$ and R10, which have comparable curvatures at crushing. Assuming the initial stiffness for the prestressed member is the same as that for the reinforced concrete member, the ductility factor at crushing for each member will be approximately $\mu_{1}=\mu_{2}=4.75$. From substitution in equation $(21), \frac{F_{2}}{F_{1}}=1.288$. The value of $F_{1}$ corresponding to the yield moment for Rio is $\frac{\mathrm{M}}{\mathrm{bd}^{2}}=825$. Therefore the required value of $\mathrm{F}_{2}$ is $\frac{\mathrm{M}}{\mathrm{bd}^{2}}=1062$. This value is less than the actual maximum moment of resistance of $\frac{\mathrm{M}}{\mathrm{bd}^{2}}=$
1298 for $\mathrm{p} 4$.

On the basis of Rosenbleuth $s$ expression it may be concluded that a prestressed concrete member designed to the same maximum moment capacity as a comparable reinforced concrete member undergoes greater ductility demands than the reinforced concrete member, but these are more than allowed for by the greater ductility available before crushing.

\section{Analytical Study of Columns}

4.1 Comparison of Theory and Experimental Results

The experimental moment-curvature relationships obtained from the columns of Units 3 and 4 during the cyclic loading tests are jllustrat ed in Figs, 11 and 12. The experimental curves were plotted in each case for the plastic hinge length directly above the beam since the largest values of curvature were measured over this gauge length. Experimental moments were taken at the section 3 above the top of the beam as this represented the critical section for crushing.

Figs. 11 and 12 also show the theoretical curves. The experimental axial loads were increased with increasing bending moment, and the same increasing axial load relationship was used in the theory. In the theory it was found that at far advanced curvatures the 
strands in the compression zone attained quite large compressive strains. Little is known about the behaviour of prestressing wires or strands in compression within a flexural member. For reinforced concrete it is generally assumed that the shape of the stress-strain curve for tension will also apply in compression.

Buckling is considered to by delayed by:

(a) the presence of some concrete around the bars.

(b) the necessity for a compression bar in a plastic hinge zone to undergo a reverse curvature to buckle during flexure.

Prestressing wires or strands are more 1ikely to buckle than reinforcing bars because of their higher stress levels and lower moments of inertia due to smaller diameters. The stressstrain relation assumed for steel in compression in the theory is illustrated in Fig. 13. The prestressing strand in compression is assumed to follow the initial slope of the stressstrain curve up to a strain of -0.005 and then to retain the compressive stress achieved at that strain with further increase in strain. This effect becomes significant only at very large curvatures. This assumption appeared to give the best correlation with the experimental results of Units 3 and 4 . The value for ultimate steel strain in tension assumed in the theory was 0.031 from correlation with test results.

A value of $\varepsilon_{0}=0.0025$ for the concrete was used in the theory for Units 3 and 4 . This value was found from the concrete control tests on standard cylinders, and arises because of the high strength of the concrete ( $f:=8000$ p.s.i.l.

The column of Unit 3 contained ties which satisfied normal prestressed concrete code requirements for shear and gave a $\mathrm{Z}$ value for the core of 67. Three theoretical models for the compressed concrete are compared in the curves of Fig. 11. The closest correlation of theory with experiment for the column of Unit 3 came from Model 1. This is reasonable as for this column at the plastic hinges there was a gradual propagation of longitudinal cracking in the compression zone rather than sudden spalling of the cover concrete. The discrepancies between the experimental and theoretical curves at large curvatures may be due to the fact that the experimental values were determined from cyclic rather than monotonic load. ing. The bottom strand first goes beyond the elastic limit at the peak of cycle 5 and its subsequent behaviour will vary from monotonic characteristics.

The column of Unit 4 contained heavy rectangular spirals which gave a $z$ value for the theory of 5. The cover concrete of this column spalled suddenly during the tests. As would be expected, the best correlation with experiment for this column was obtained by assuming that the cover concrete spalled at a strain greater than 0.004 . This model gave close agreement between theory and experiment as can be seen in Fig. 12 .

\subsection{Variation of Ductility with Axial Load}

The effect of axial load on ductility is important when considering the behaviour of prestressed concrete columns. To provide a eomparison, a study was made of the sections with transverse confinement satisfying normal prestressed concrete codes as represented by the best Unit 3 model, and sections with special transverse reinforcement for confinement complying with the best unit 4 model. Interaction and ductility curves are shown plotted for both cases in Figs. 14 and 15 . It may be readily seen that the degree of confinement has little effect on the interaction curves and not a large effect on curvature at maximum moment。 To give an indication of the ductility available after maximum moment, curvatures at half maximum moment on the falling branch of the moment-curvature response are also plotted in Figs. 14 and 15. It may be seen that increasing the axial load from zero initially causes the curvature at half maximum moment to increase. This is because fracture of the tension steel wires is the cause of the rapid drop of moment at low axial loads and the curvature at steel fracture increases as the neutral axis depth increases with load. Eventually a discontinuity is reached and at higher loads the fracture strain of the steel is not reached at half maximum moment. In this region the half maximum moment point is reached with success ively rapid reduction in curvature with increasing axial load. The shape of the momentcurvature relations with varying axial loads are shown in Fig. 16. It is interesting to note that the point of maximum curvature on Fig. 14 occurs at an axial load very close to the limit specified in the SEAOC ${ }^{10}$ code

$\frac{P}{A_{g}} \ngtr 0.12 f$

above which the total ultimate moment capacity of the columns, at the design earthquake axial load, must be greater than the total ultimate moment capacity of the beams at a particular joint.

It may be concluded from the ductility curves for half maximum moment shown in Figs. 14 and 15 that concrete confinement results in

(a) an increase in the maximum ductility available from the section

(b) an increase in the range of axial load over which significant post-crushing ductility is available.

\section{General Comments}

Specific conclusions have already been given at the end of each section and some general comments will now be made on prestress. ed concrete seismic design in light of the results presented.

One of the major concerns expressed about the ability of prestressed concrete as a seismic resistant material has been whether or not it can undergo large post-elastic deformations. The results presented here have shown that prestressed concrete beams and columns can exhibit large ductility, provided limits of steel ratio and axial load are not exceeded.

The other major concern has been the elastic recovery of prestressed concrete members and hence their small energy dissipation. An indication of the energy dissipation capacity of prestressed concrete members may be obtained from Figs. 17 and 18, which 
152

show the hysteresis loops for the Unit 2 beam and the Unit 4 column. The initial cycles in both cases showed low energy dissipation. Once crushing of the concrete fibres occurs there is a significant reserve of energy dissipation available, but at the expense of incurring structural damage. Because of the difficulty of repairing members back to a fully prestressed condition it is desirable that curvatures should not reach values where the concrete will crush under a severe earthquake.

It is generally accepted that the response of a prestressed concrete structure to a given earthquake will be greater than that of a comparable reinforced concrete structure. because of the lower energy dissipation and viscous damping properties for prestressed concrete. Hence it may be argued that the load factors for seismic design should be higher for prestressed concrete than for reinforced concrete rather, than equal as is the case in the ACI codeb, ?

It must be noted, however, that because of higher concrete strengths a prestressed concrete member may sustain greater curvatures before crushing than a comparable reinforced concrete member. This factor may well counteract the effect of the smaller energy dissipation capacity under cyclic loading. only dynamic analyses to be carried out in the future wil give the final answer but it may be that the use of a higher load factor for prestressed concrete as is recommended by the NZPCI 1 can only be justified on the grounds that the difficulty of repair, and hence the desirability of avoiding structural damage, is greater for a prestressed concrete structure than for a reinforced concrete structure.

\section{Acknowledgements}

This work was carried out in the Department of Civil Engineering of the University of Canterbury by the first named author during postgraduate studies supervised by the second named author. The encouragement of Mr. R. Shepherd and the financial assistance of the New Zealand University Grants Commitee, the New Zealand portland Cement Association and the Ministry of Works, are gratefully acknowledged.

\section{References}

1. Blakeley, R. W. G., Park, R. and shepherd, R.: "Seismic Resistance of Prestressed Concrete". Bulletin of the New Zealand Society for Earthquake Engineering, Vol. 3 , No. 1, March 1970, pp.3-23.

2. Lin, $T$. $Y$. "Earthquake Engineering", co-ordinating editor, Robert $L$. Wiegel; Chapter 19, pp.475-494. Published by Prentice-Hal1, Inc.s 1970 .

3. Blakeley, $R_{\text {w }}, G$ and Park, $R$ : "Seismic Resistance of Prestressed Concrete BeamColumn Assemblies", Submitted to Journal of American Concrete Institute.

4. Kent, D. C. and Park, R: "Inelastic Behaviour of Reinforced Concrete Members with Cyclic Loading", New Zealand National Conference on Earthquake Engineering, May 1971 .

5. Priestley, M. J. N. Moment Redistribution in Prestrossed Concrete Continuous Beams", Ph.D. Thesis, University of Canterbury, 1966.
6. ACI 318.63: "Building Code Requirements for Reinforced Concrete", American Concrete Institute, 1963.

7. ACI Committee 318: "Proposed Revision of ACI 318-63: Building Code Requirements for Reinforced Concrete", ACI Journal No. 2 Proc. V.67, February, 1970.

8. Kent, Do C.: Inelastic Behaviour of Rein forced Concrete Members with Cyclic Loading , Ph。D. Thesis, University of Canterbury, 1969.

9. Rosenbleuth, E.: Personal communication to A. Lo Andrews, March, 1968 .

10. SEAOC: Recommended Lateral Force Requirements. Seismology Committee, Structural Engineers Association of California, 1968 .

1. N.Z.P.C.I.: "Seismic Design Recommendations for Prestressed Concrete" N.Z. Prestressed Concrete Institute, 1966.

Appendix: Details of Experiments on Cyclic Loading of Prestressed Concrete Beam-Column Assemblies

A series of four tests were conducted on full size precast, prestressed concrete beamcolumn assemblies under reversed cyclic loading of high intensity. The test specimen was part of a multistorey prestressed concrete frame as illustrated in Fig。 19. The axial column load $P$ represents the loading from gravity and overturning moment; the reversible load $X$ applied at the end of the beam and the reactive lateral loads $H$ induced at the ends of the column represent the shears applied in an earthquake. Static cyclic loading with rotations at the critical sections of up to 15 times the cracking rotation were applied to the test specimens. Figs. 20 and 21 show the design details of the members. Units 1 and 2 were designed to form plastic hinges in the beam at the joint and Units 3 and 4 were designed to form plastic hinges in the column immediately above and below the joint. The columns were pretensioned; the beams were lightly pretensioned for handling purposes and post-tensioned by cables passing through the column into an exterior anchorage block. One inch thick moist pack mortar joints were formed between the members before posttensioning. The cables were grouted. The steel stirrups and ties in Units 1 and 3 were designed to satisfy the commonly used codes for prestressed concrete, for example ACI 318-636. To examine the effect of concrete confinement, Units 2 and 4 contained in the column regions adjacent to the joint approximately one half of the rectangular spiral steel required by the code of the Structural Engineers Association of Californialo for special transverse reinforcement for ductility of reinforced concrete members. The beams of Units 2 and 4 also contained extra stirrups as required by the SEAOC code 10 for reinforced concrete.

\section{Notation}

$A_{g} \quad$ gross area of cross section

As total steel area

$A_{51} A_{52}, A_{53} \ldots$ area of steel at tendon

b width of cross section

$b^{n}$ width of confined core measured to outside of hoops

C 


$$
\begin{aligned}
& \mathrm{D}_{1}, \mathrm{D}_{2} \\
& \mathrm{D}
\end{aligned}
$$

d

Es

$F_{1}, F_{2}$

${ }^{f}$

$f:$

$f_{s}$

$f_{\text {sa }}$

$f_{s b}$

$f_{\text {se }}$

$\mathrm{f}_{\mathrm{sp}}$

f

$f_{y}$

$\mathrm{K}$

$\mathrm{k}$

M

$\mathrm{M}_{\mathrm{Cr}}$

$\mathrm{Mu}$

N

$\mathrm{P}$

$\mathrm{p}$

$\mathrm{p}^{\text {m }}$

$\mathrm{s}$

$T_{c}$

$T_{\text {S }}$

y

z

$\mathrm{Z}_{\text {core }}$

${ }^{2}$ cover

$a_{1}, a_{2}, a_{3}, \ldots$ distance from tendon

Y

$\varepsilon_{\mathrm{c}}$

$\varepsilon_{c c}$

$\varepsilon_{\mathrm{r}}$

$\varepsilon_{\mathrm{S}}$ position $1,2,3, \ldots .$. to

extreme compression fibre/D

overall depth

aximum deflection of systems 1 and 2

distance to centroid of prestressing steel from extreme compression fibre

modulus of elasticity of steel.

maximum forces for systems 1 and

stress in concrete

strength of $6^{\prime \prime}$ diameter by $12^{\prime \prime}$ cylinder

stress in steel.

see Fig. 2

see Fig。 2

stress in steel due to prestress

stress in prestressing steel at maximum moment as defined by ACI code $6, ?$

ultimate steel stress

yield stress of reinforcing steel

initial stiffness of systems 1 and 2

distance from neutral axis to extreme compression fibre/D

moment

moment at cracking

maximum moment capacity

number of tendon positions

axial load

$A_{S} / b D$

ratio of volume of steel hoops to volume of confined concrete

spacing of confining steel

tension force in concrete

tension force in steel

distance to a fibre from extreme compression fibre/D

defined by equation (3)

$Z$ value for core concrete

$\mathbf{Z}$ value for cover concrete

distance from extreme compression

fibre to top of crack/D

concrete strain

concrete strain at extreme com-

pression fibre

concrete strain at rupture in

tension

steel strain $\varepsilon_{\text {sa }}$ see Fig。2。

$\varepsilon_{\text {sb }}$ see Fig。2。

$\varepsilon_{\text {su }} \quad$ ultimate steel strain

$\varepsilon_{y} \quad$ strain at a fibre

$\varepsilon_{0} \quad$ concrete strain at maximum stress

$\varepsilon_{20 \mathrm{c}} \quad$ strain at 0.2 of maximum stress on falling branch of stress-strain for concrete

$\varepsilon_{50 h}$ defined by equation (5)

$\varepsilon_{50 u}$ strain at 0.5 of maximum stress on falling branch of stress-strain for concrete and defined by equation (4)

$\varnothing \quad$ curvature or capacity reduction factor

$\phi_{\mathrm{Cr}} \quad$ curvature at first cracking

$\phi_{\mathrm{y}} \quad$ curvature at first yielding of reinforcement

$\varnothing_{.004}$ or $\phi_{\mathrm{u}}$ curvature at extreme fibre concrete strain of 0.004

$H_{1}, H_{2}$ ductility factors defined by equations (22a) and (22b). 


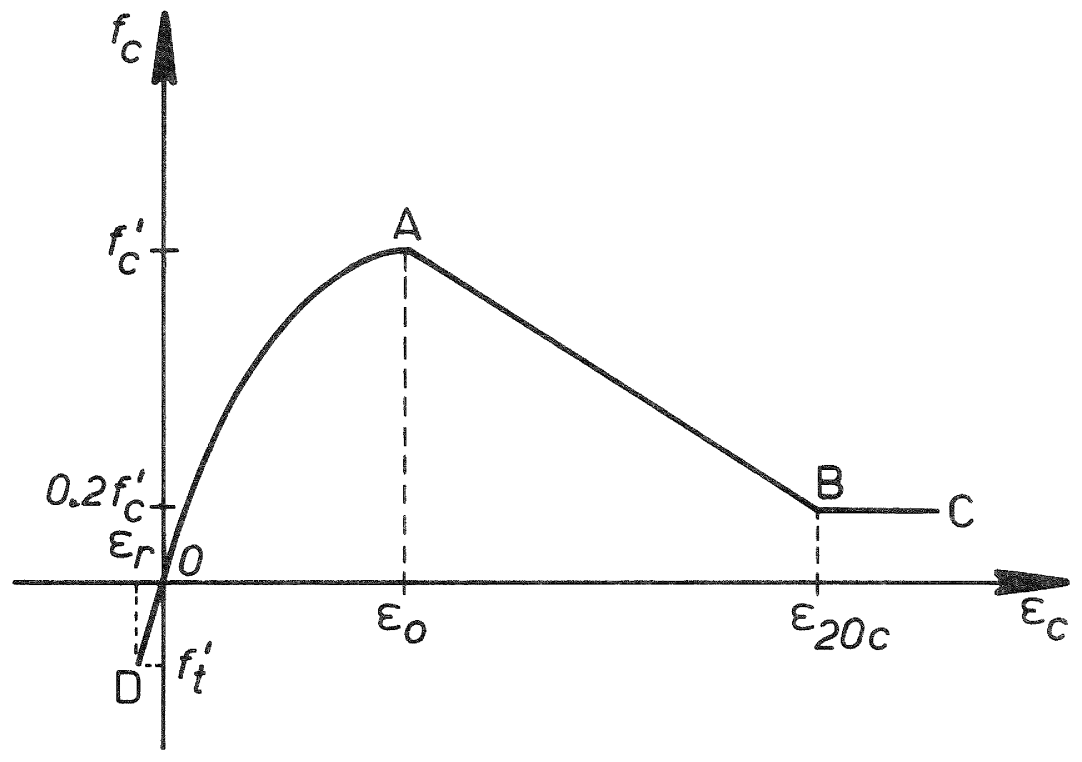

Fig. 1. Assumed Stress-Strain Relation for Concrete.

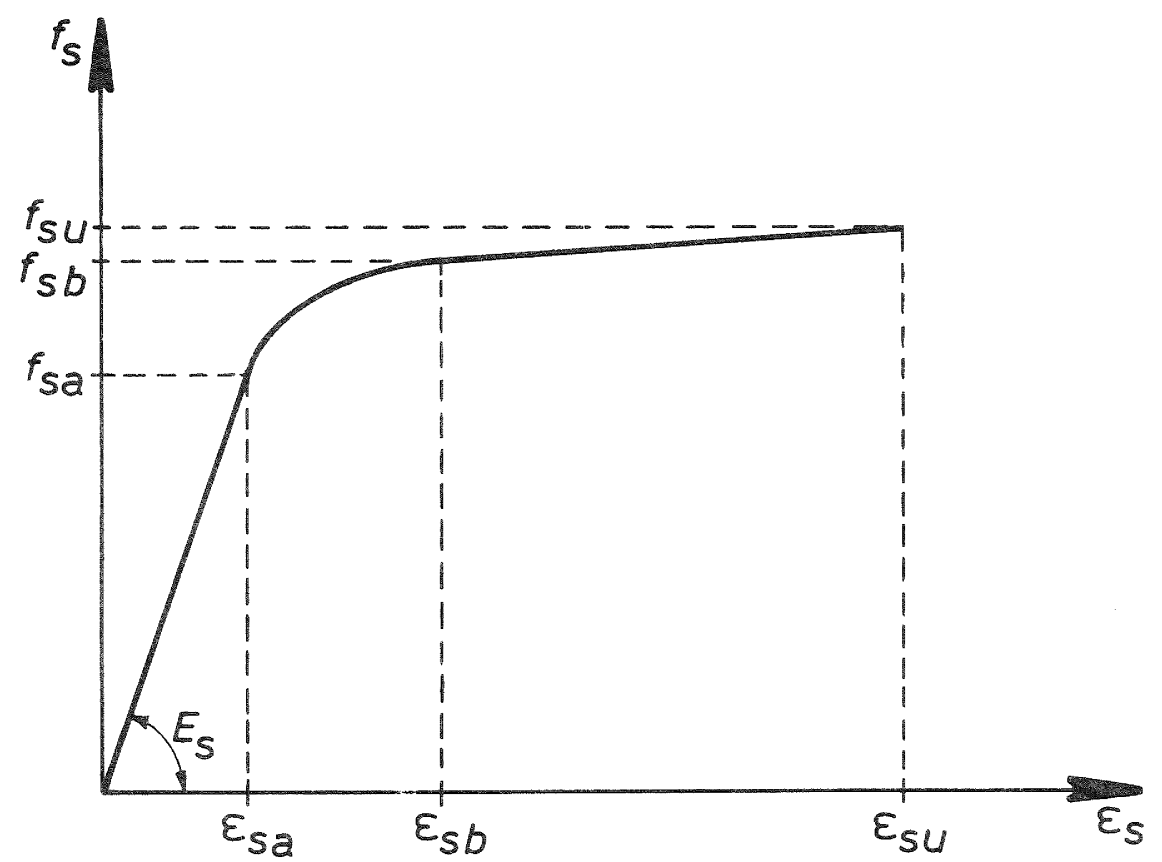

Fig. 2. Assumed Stress-Strain Relation for Prestressing Steel. 

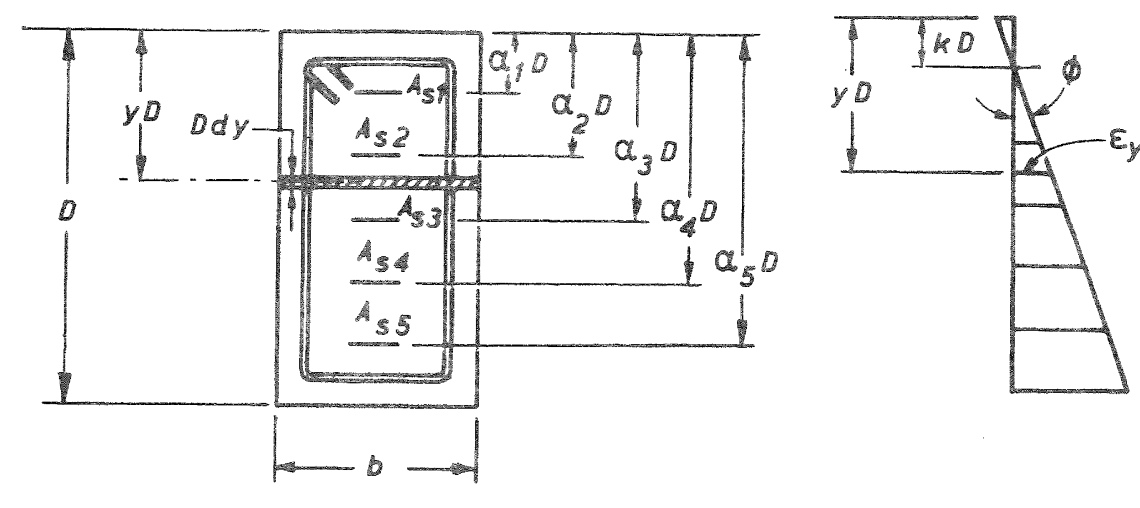

(a)
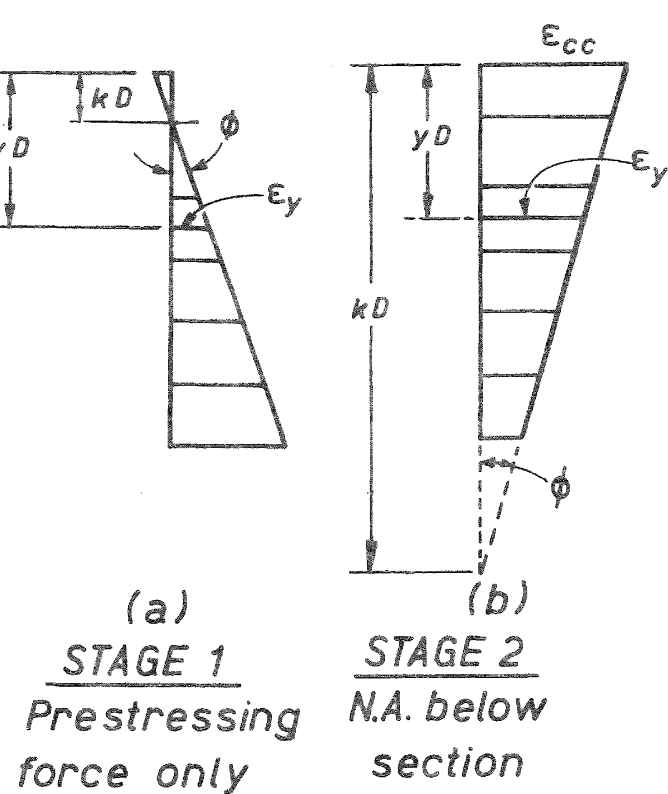

(b)

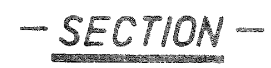

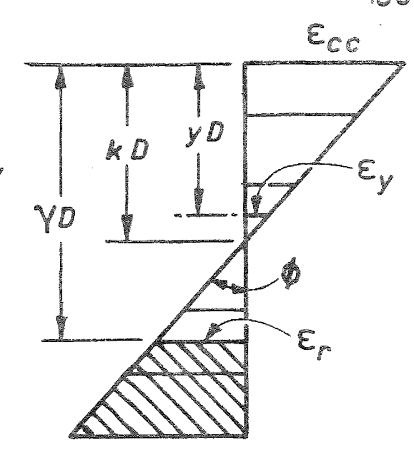

(c)

$\frac{\text { STAGE } 3}{\text { N.A.within }}$

Fig. 3. Strain Profiles for Three Stages of Loading.

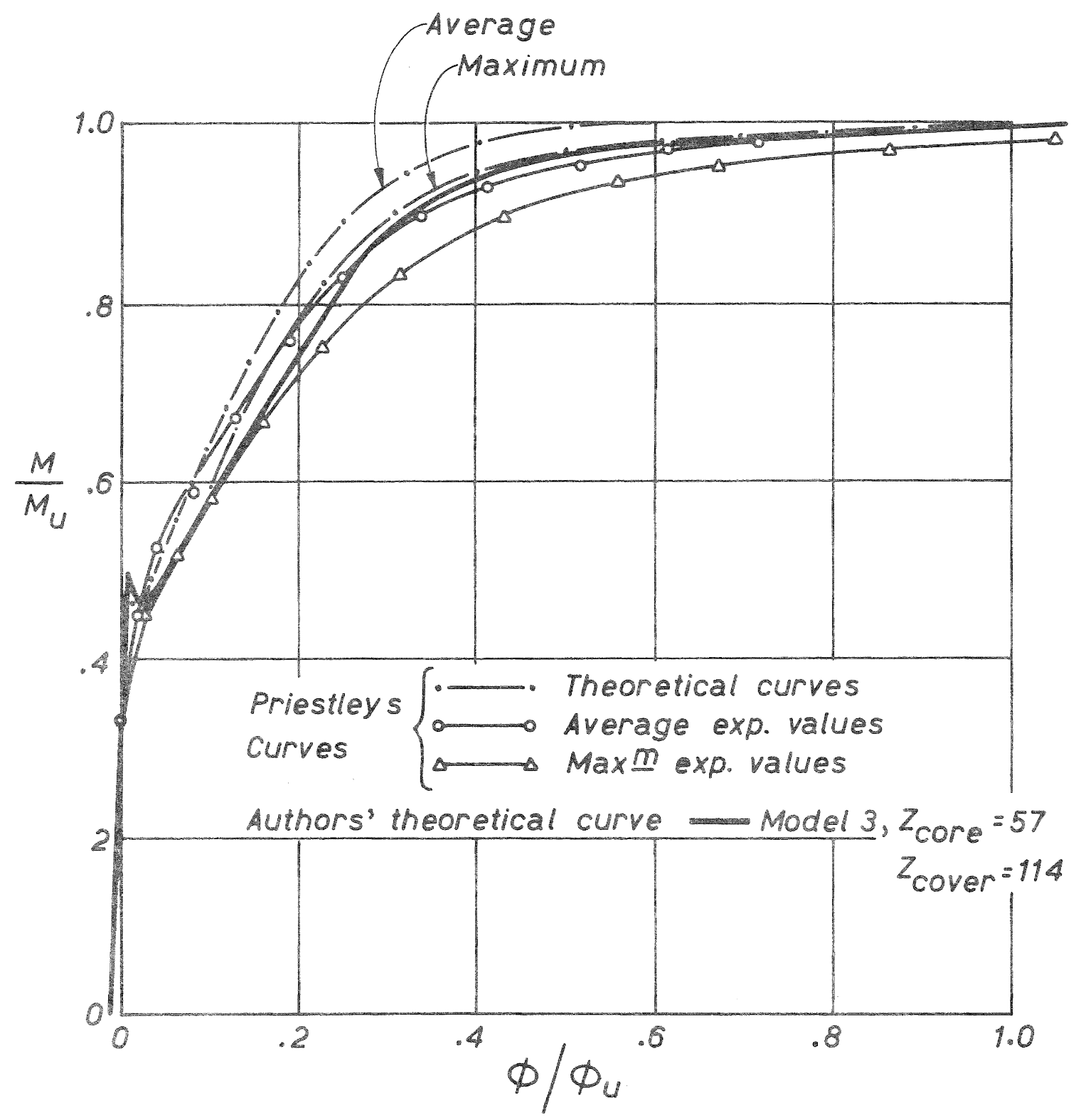

Fig. 4. Comparison with Priestley's Results for Beam MK5B in the Constant Moment Zone. 


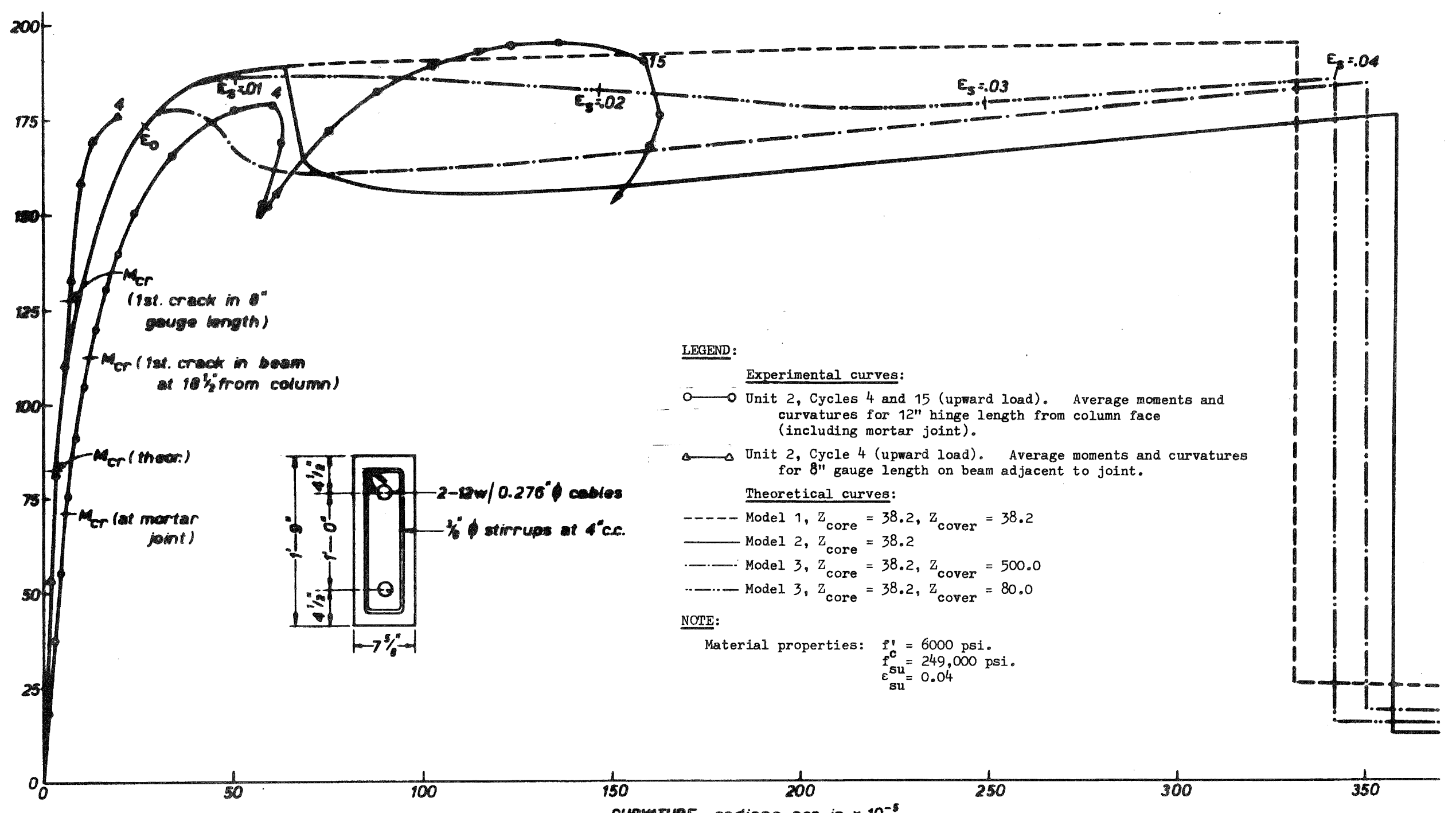

CURMTURE radians per in. $\times 10^{-5}$

Fig. 5. Comparison of Moment-Curvature Characteristics of

Unit 2 Beam and of Four Theoretical Models. 


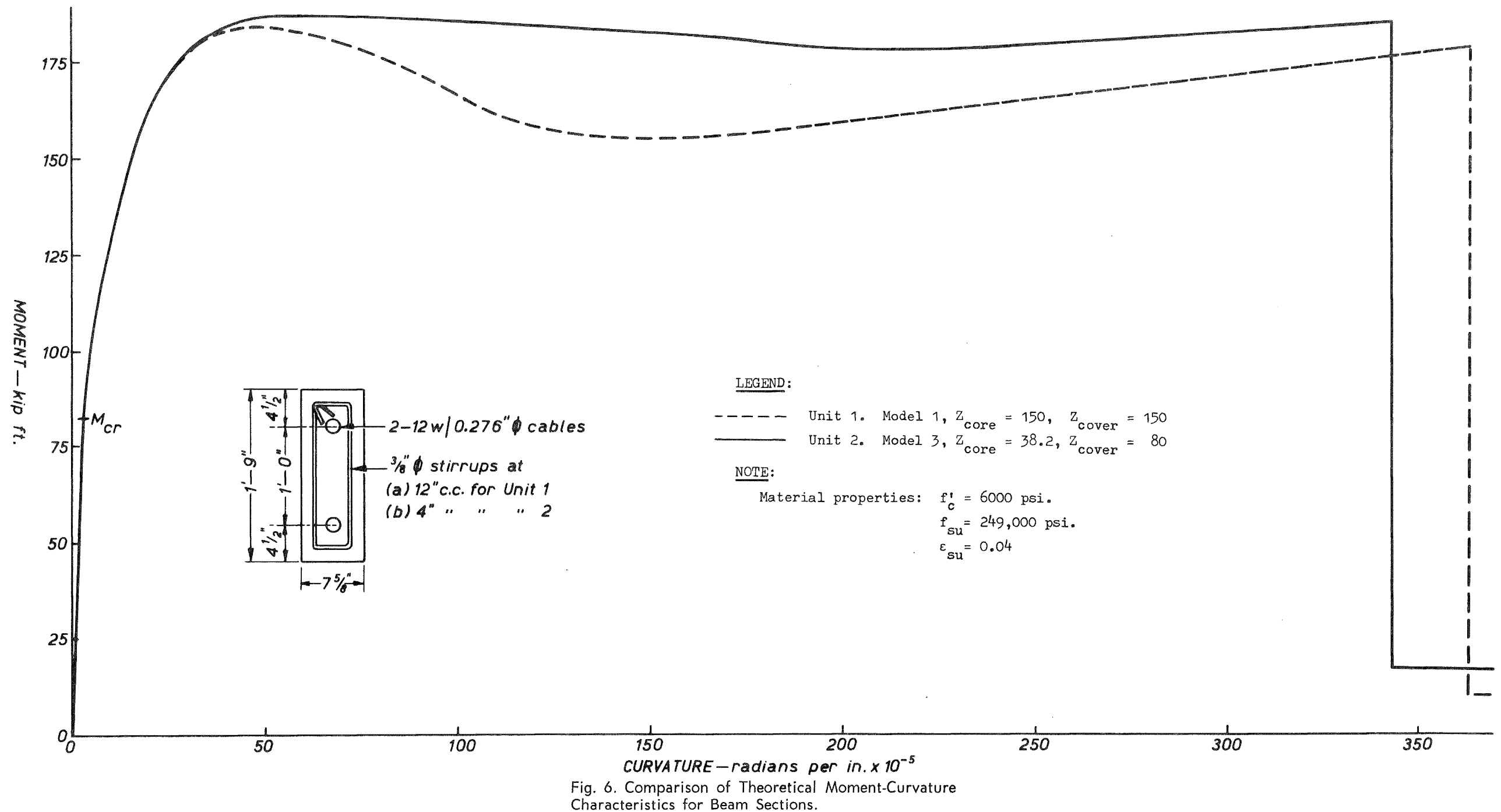




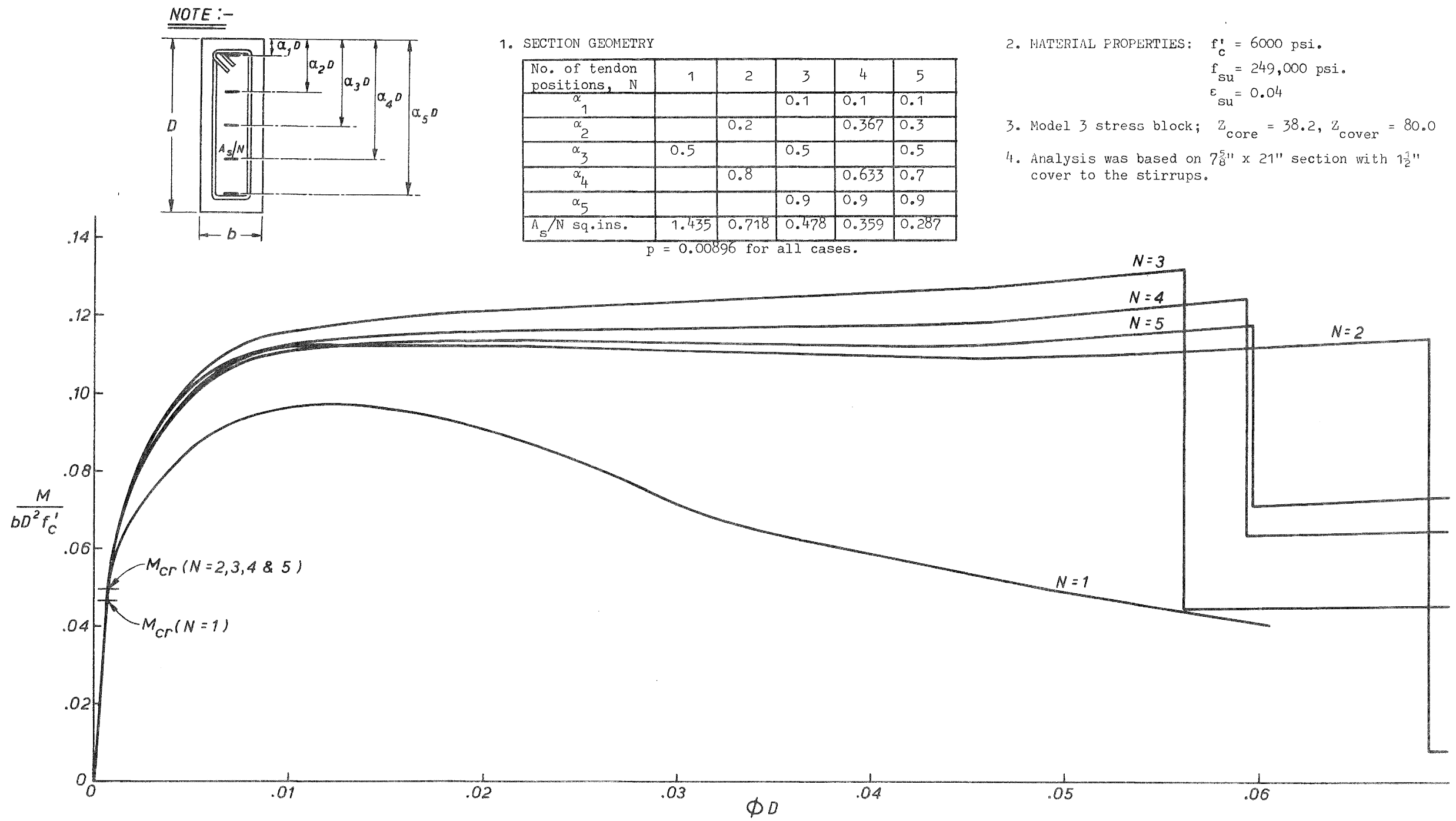

Fig. 7. Effect of Distribution of Prestressing Steel in Member. 


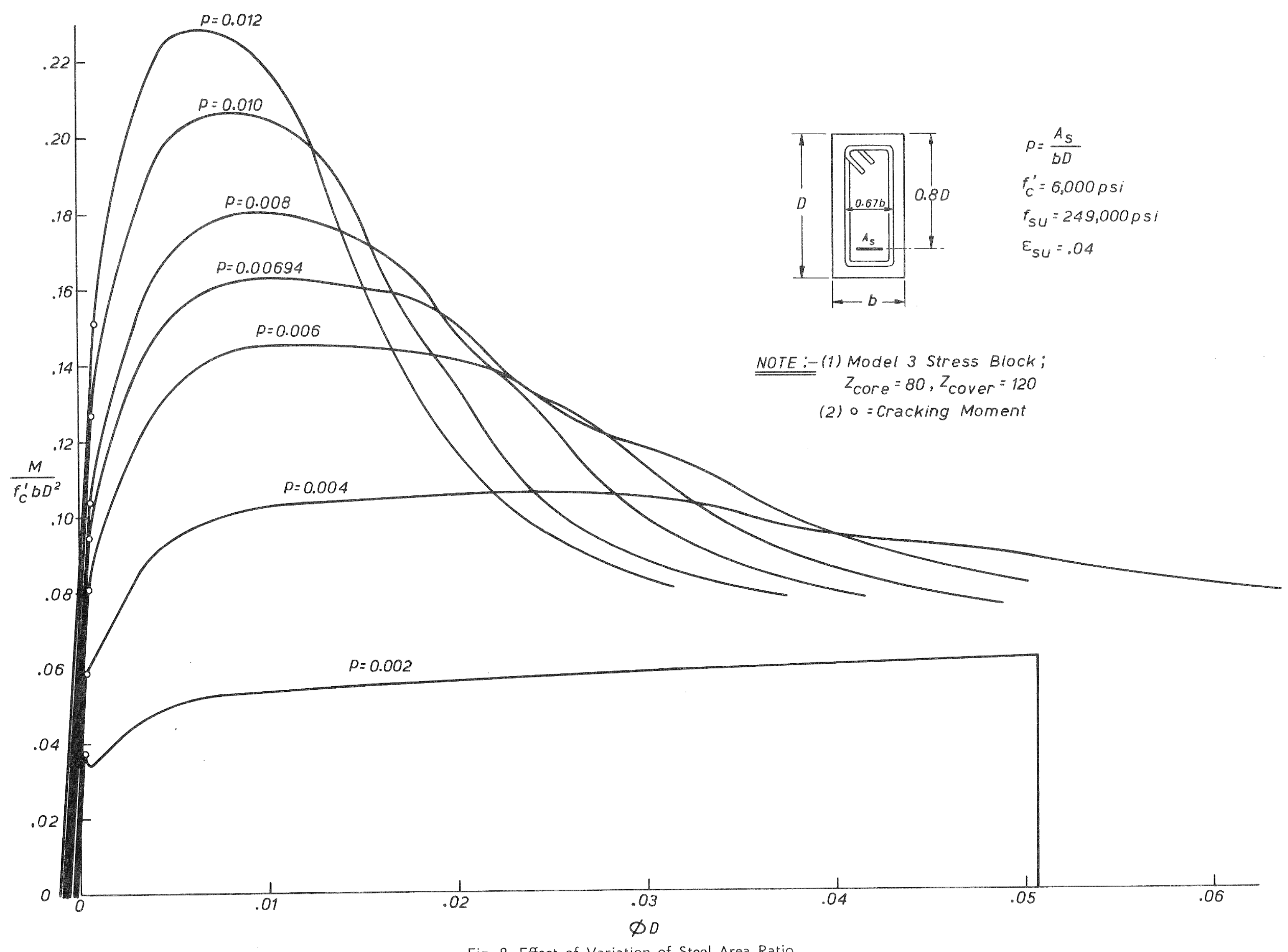

Fig. 8. Effect of Variation of Steel Area Ratio. 


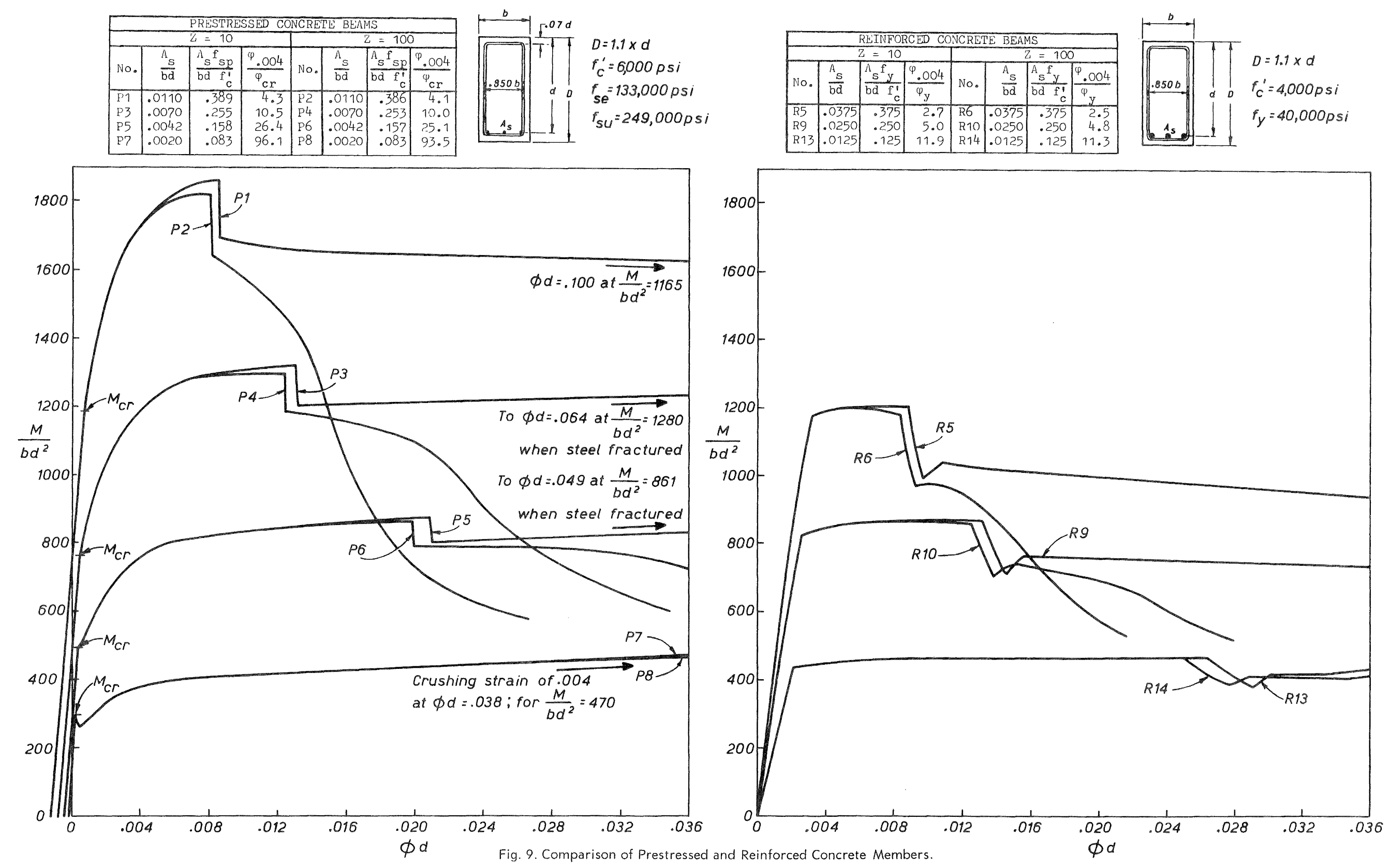




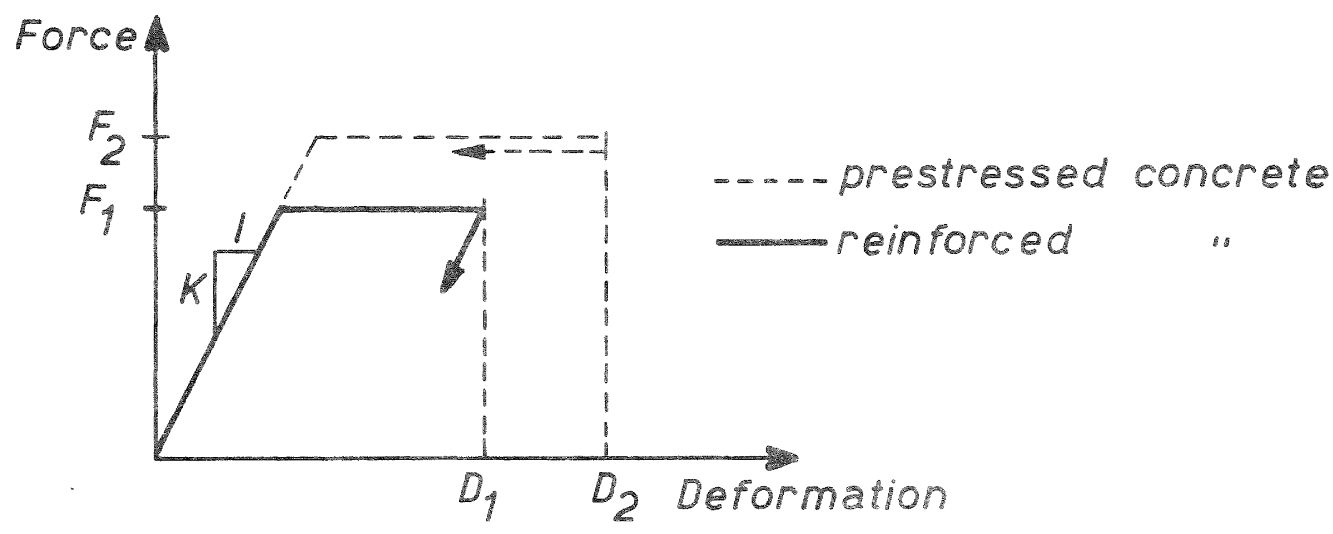

Fig. 10. Details for Rosenbleuth's Expression. 


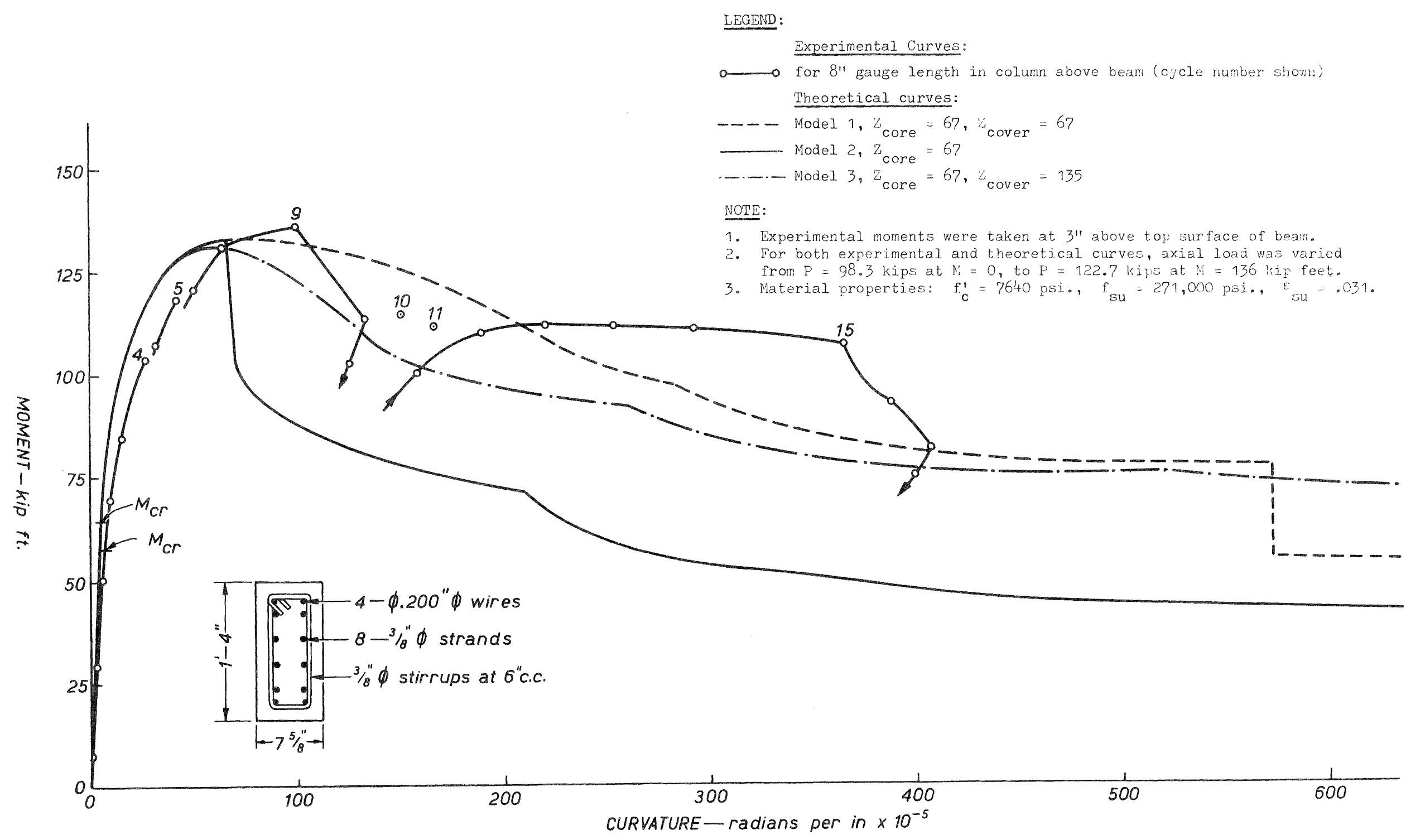

Fig. 11. Comparison of Experimental and Theoretical Curves for Unit 3 Upper Column Hinge. 


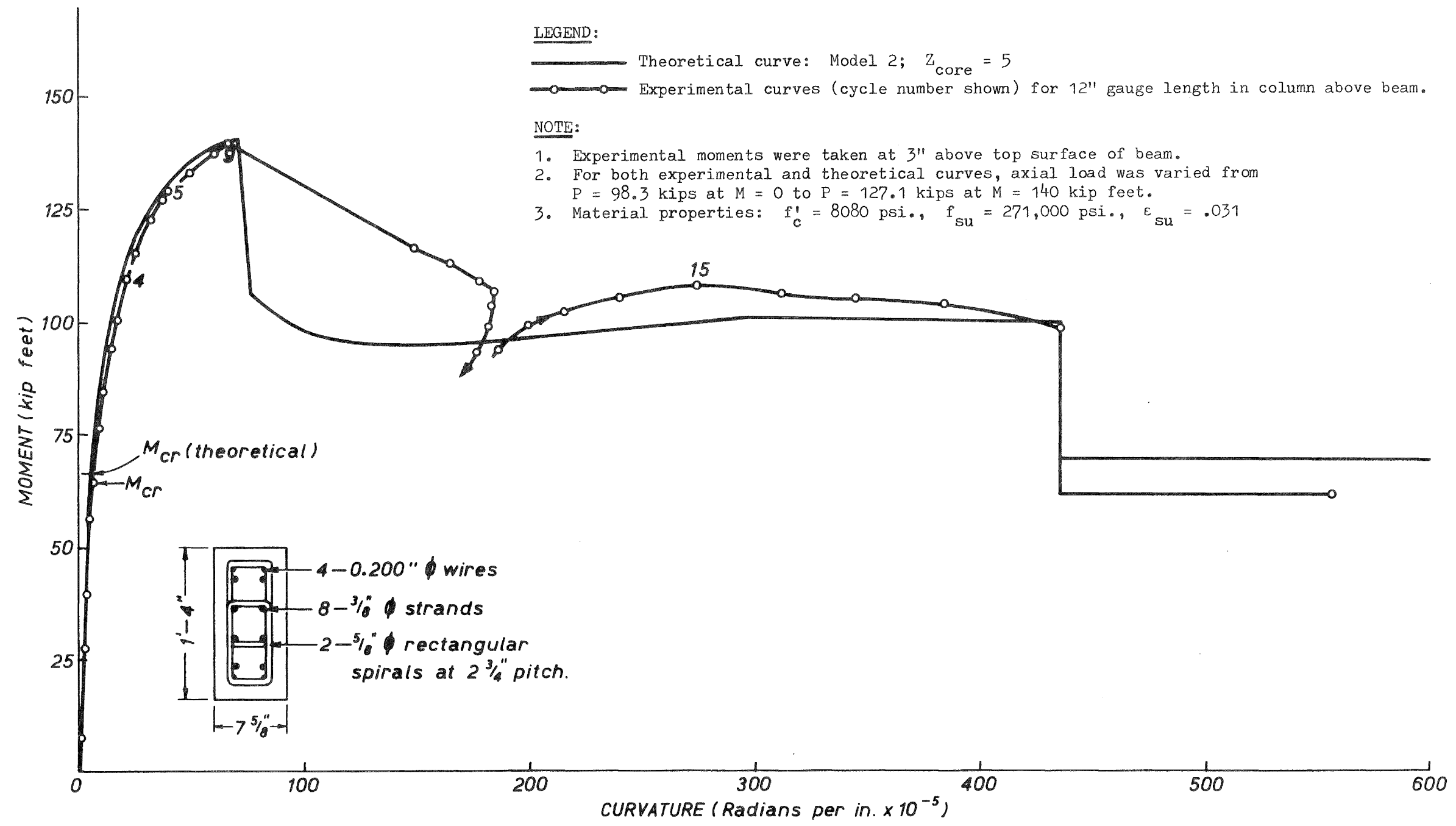

Fig. 12. Comparison of Experimental and Theoretical Curves for Unit 4 Upper Column Hinge. 


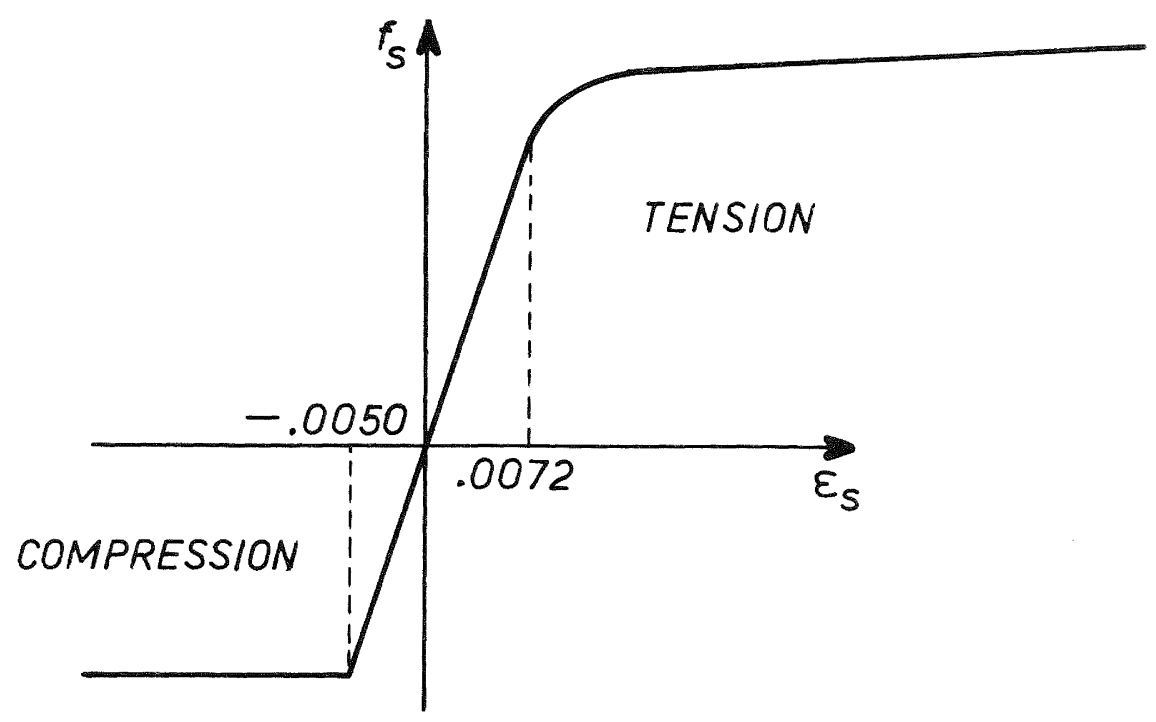

Fig. 13. Assumed Stress-Strain Curve for Prestressing Steel in Compression in Columns. 


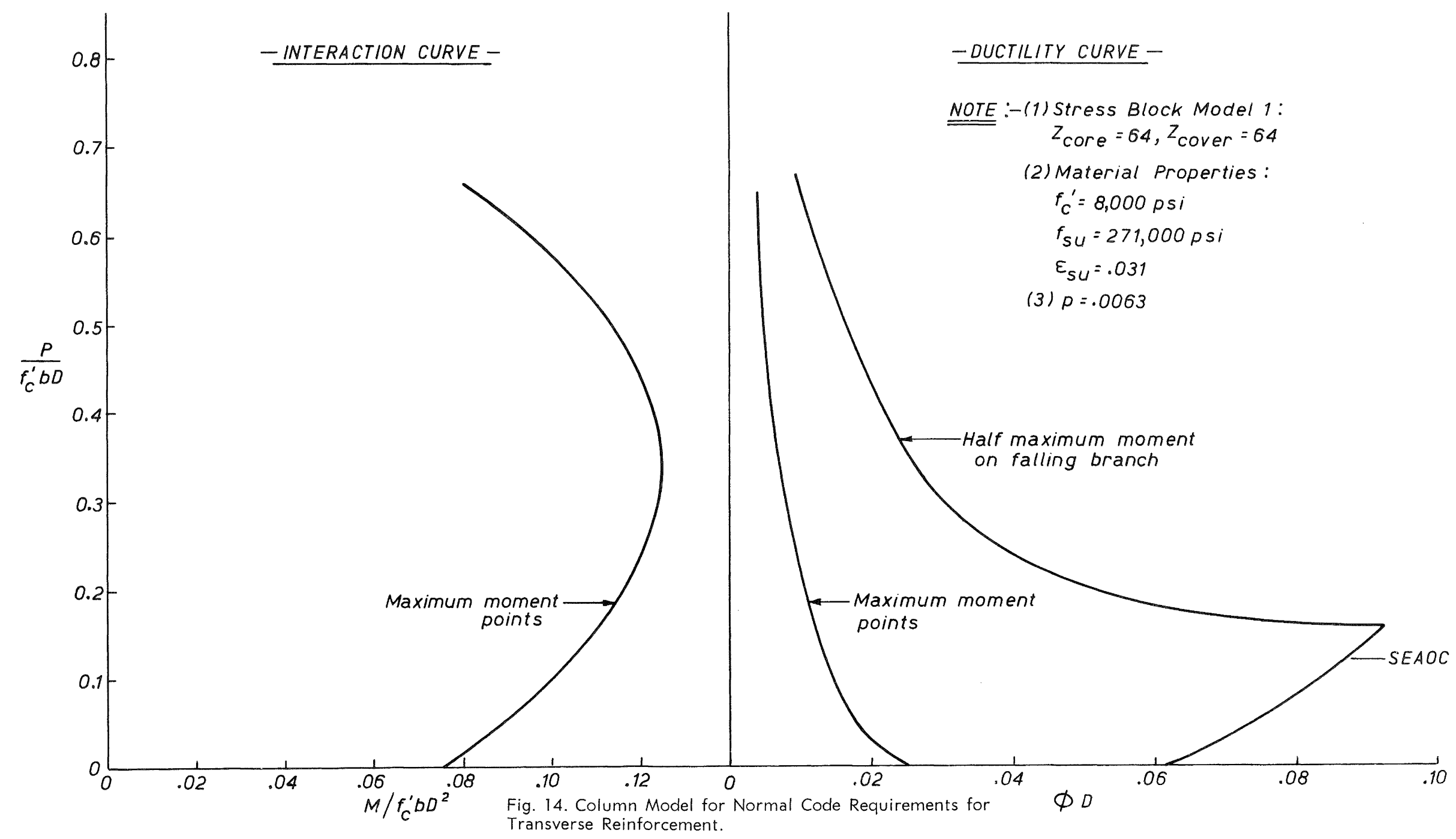




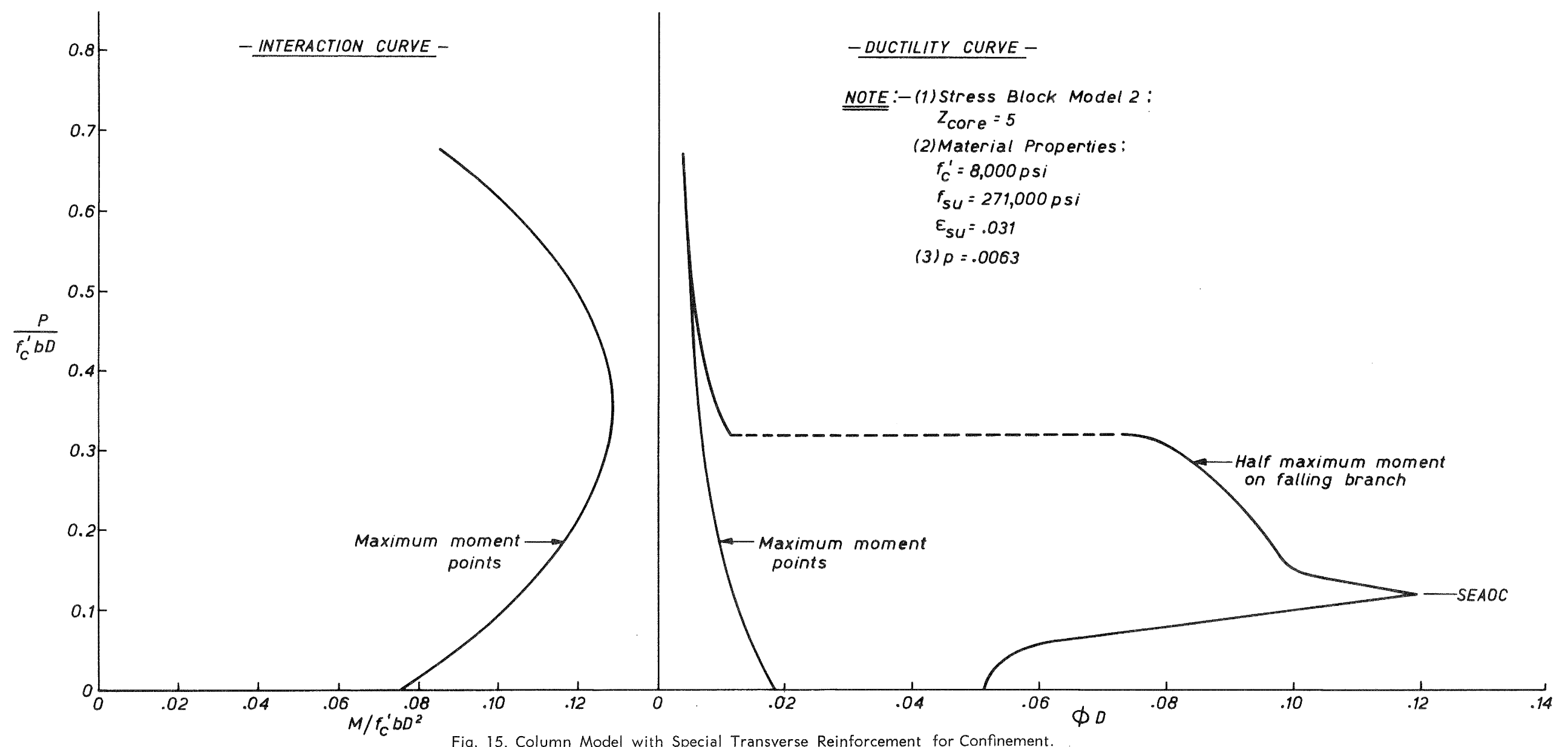




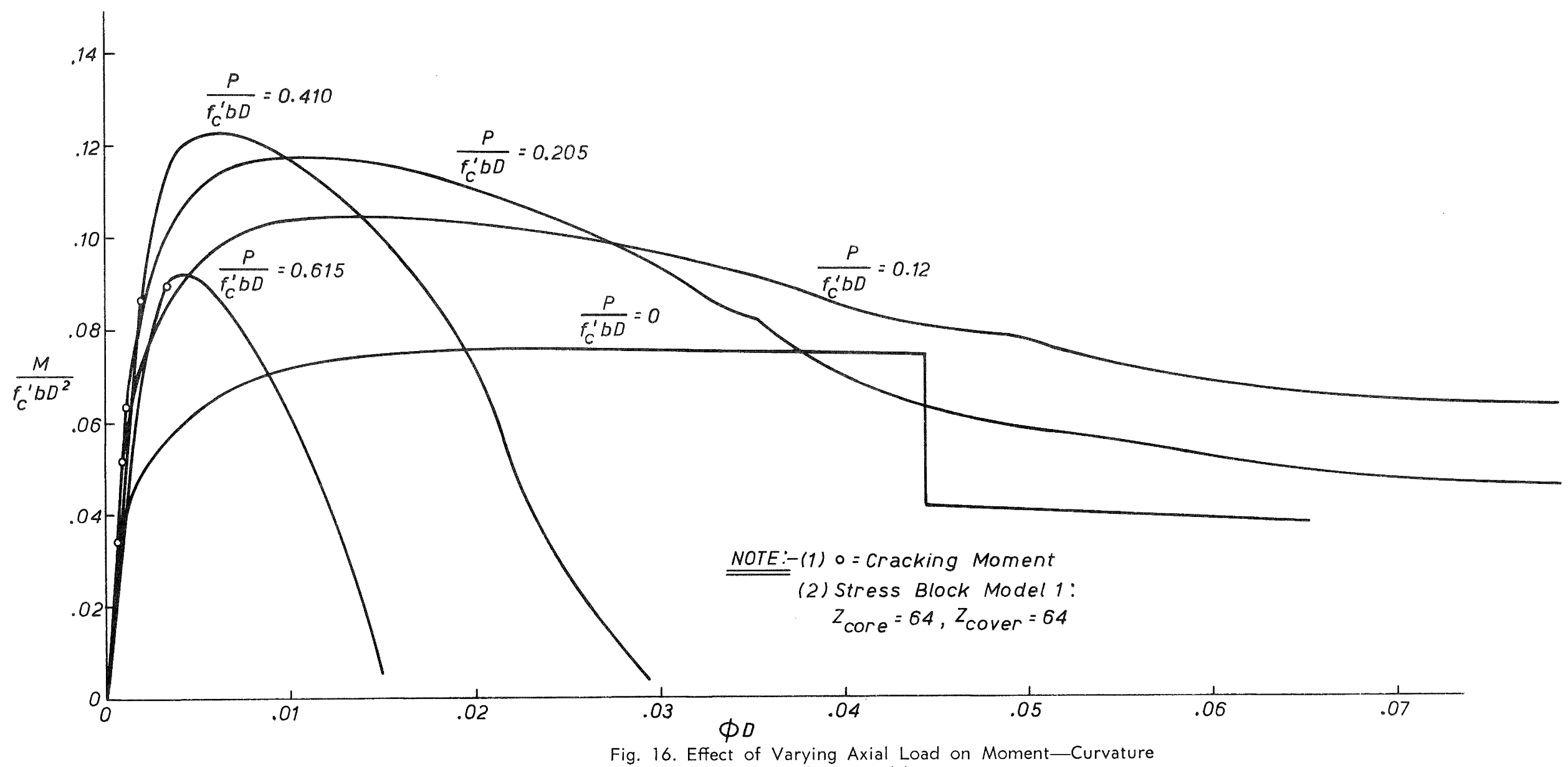

Fig. 16. Effect of Varying Axial Load on Moment-Curvature Relation for Unit 3 Column Model. 


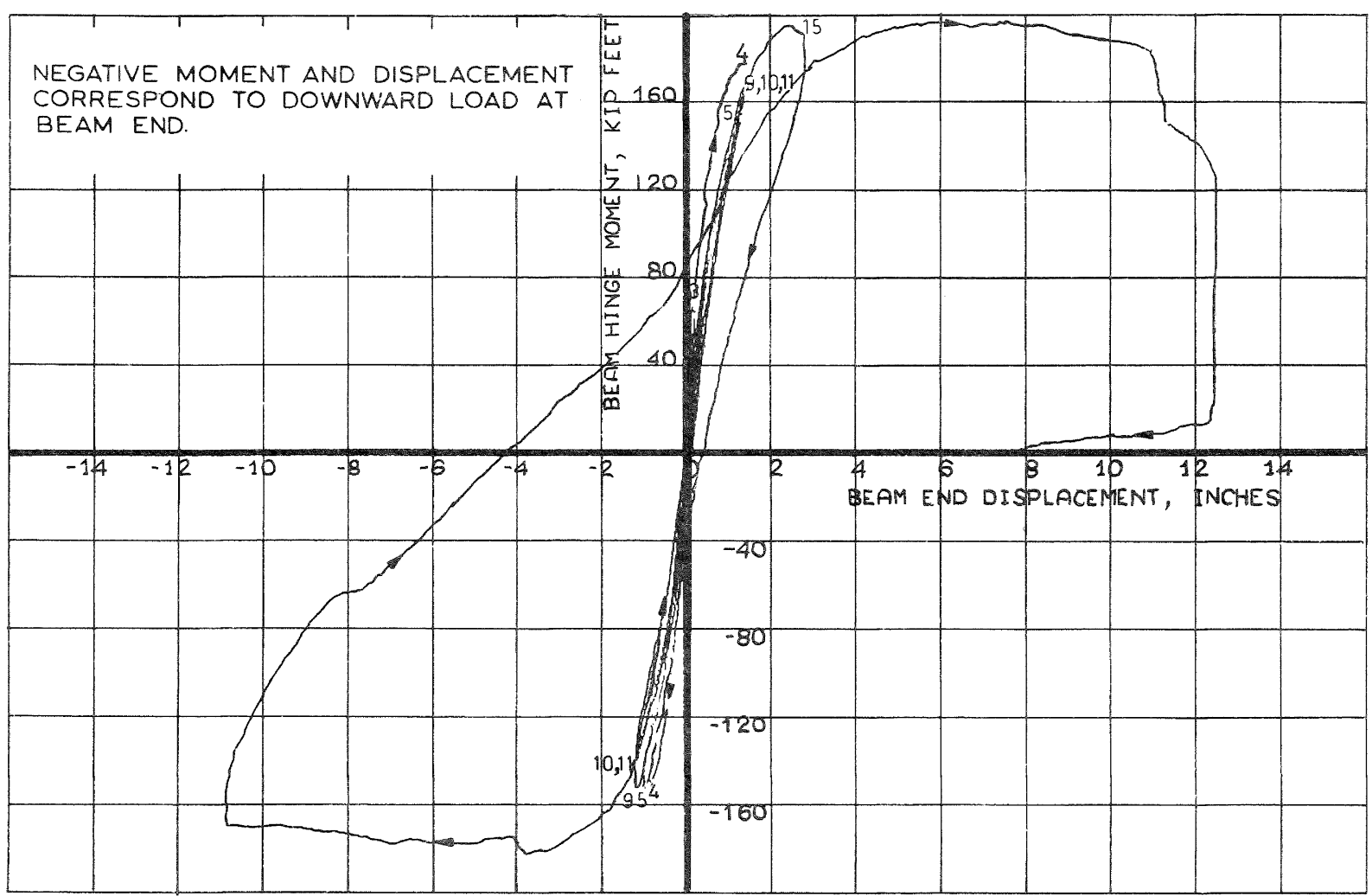

Fig. 17. Experimental Moment-Displacement Curve for Unit 2. 


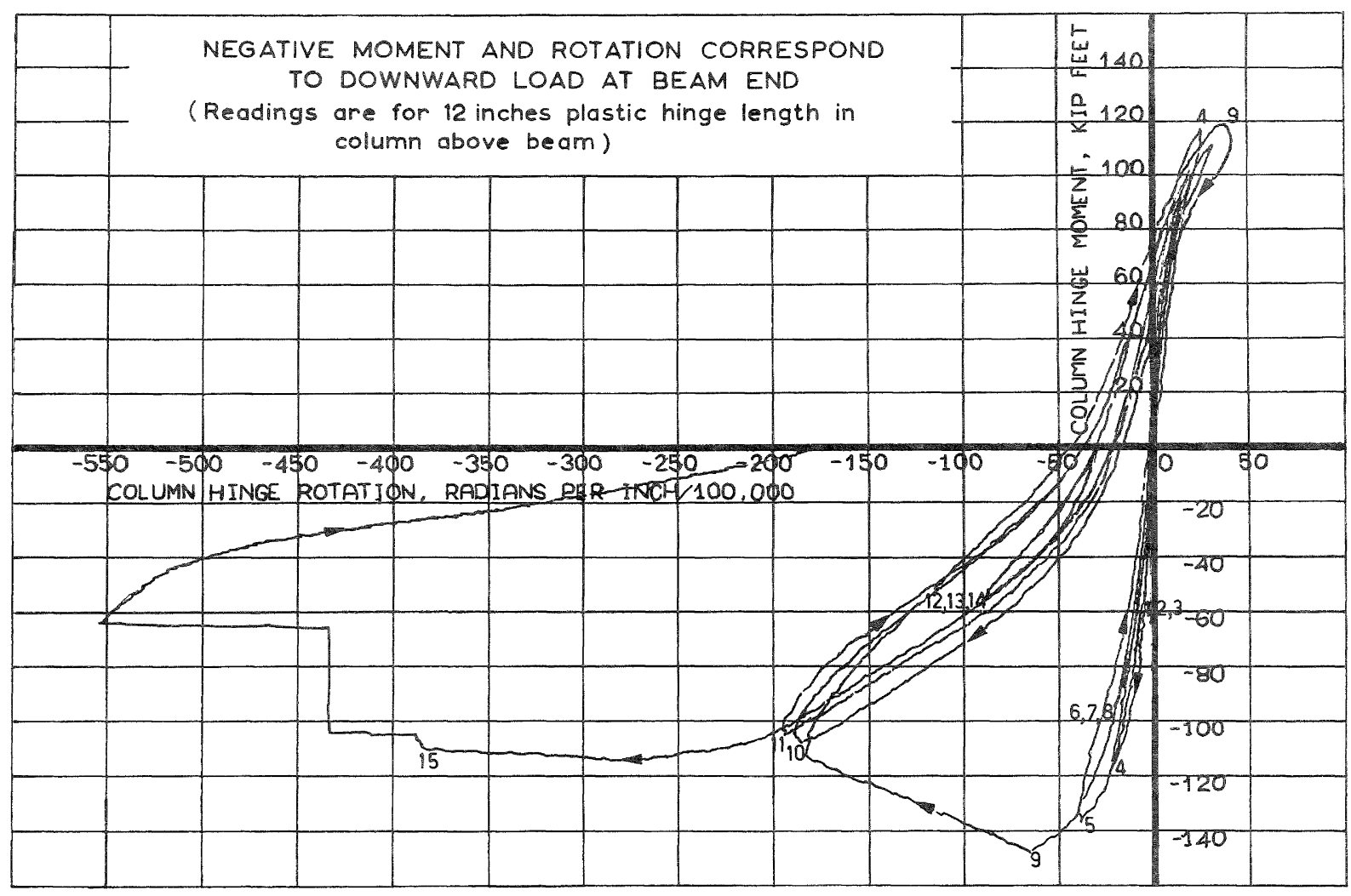

Fig. 18. Experimental Moment- Rotation Curve for Unit 4.

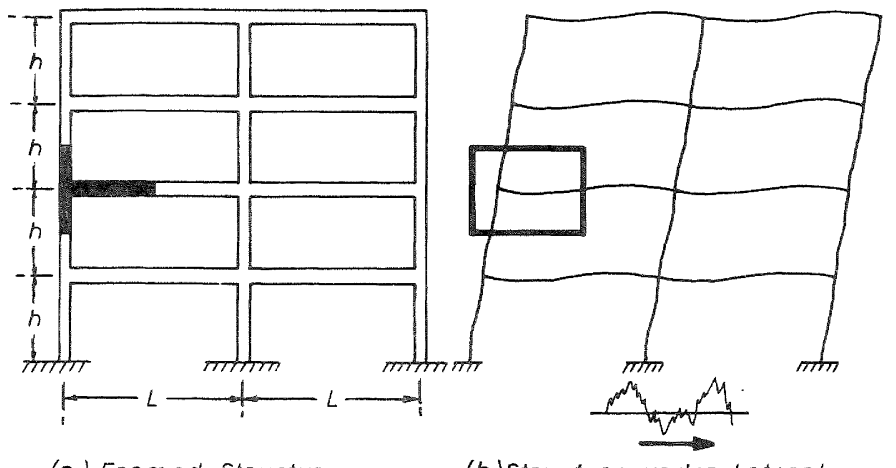

(a) Framed Structure

(b) Structure under Lateral

Earthquake Load

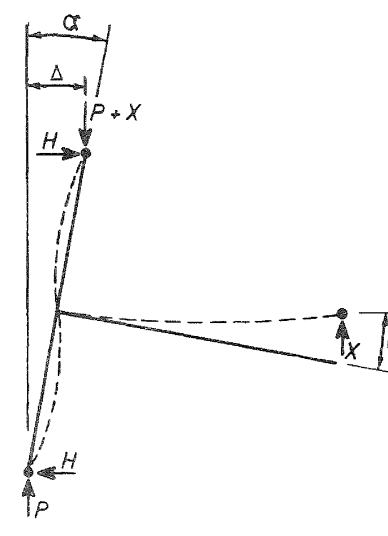

(C) Isolated Beam-Column Assembly of Frame

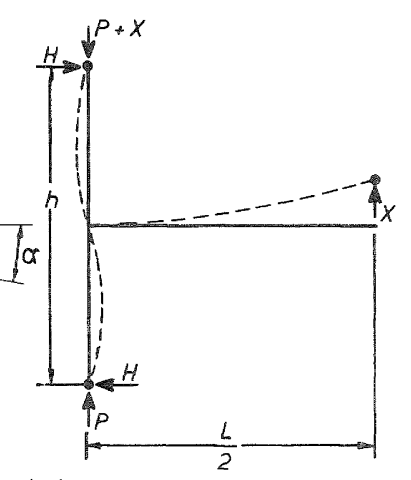

(d) Test Beam-Column Assembly Rotated through Angle $\alpha$

Fig. 19. Beam-Column Test Specimen. 

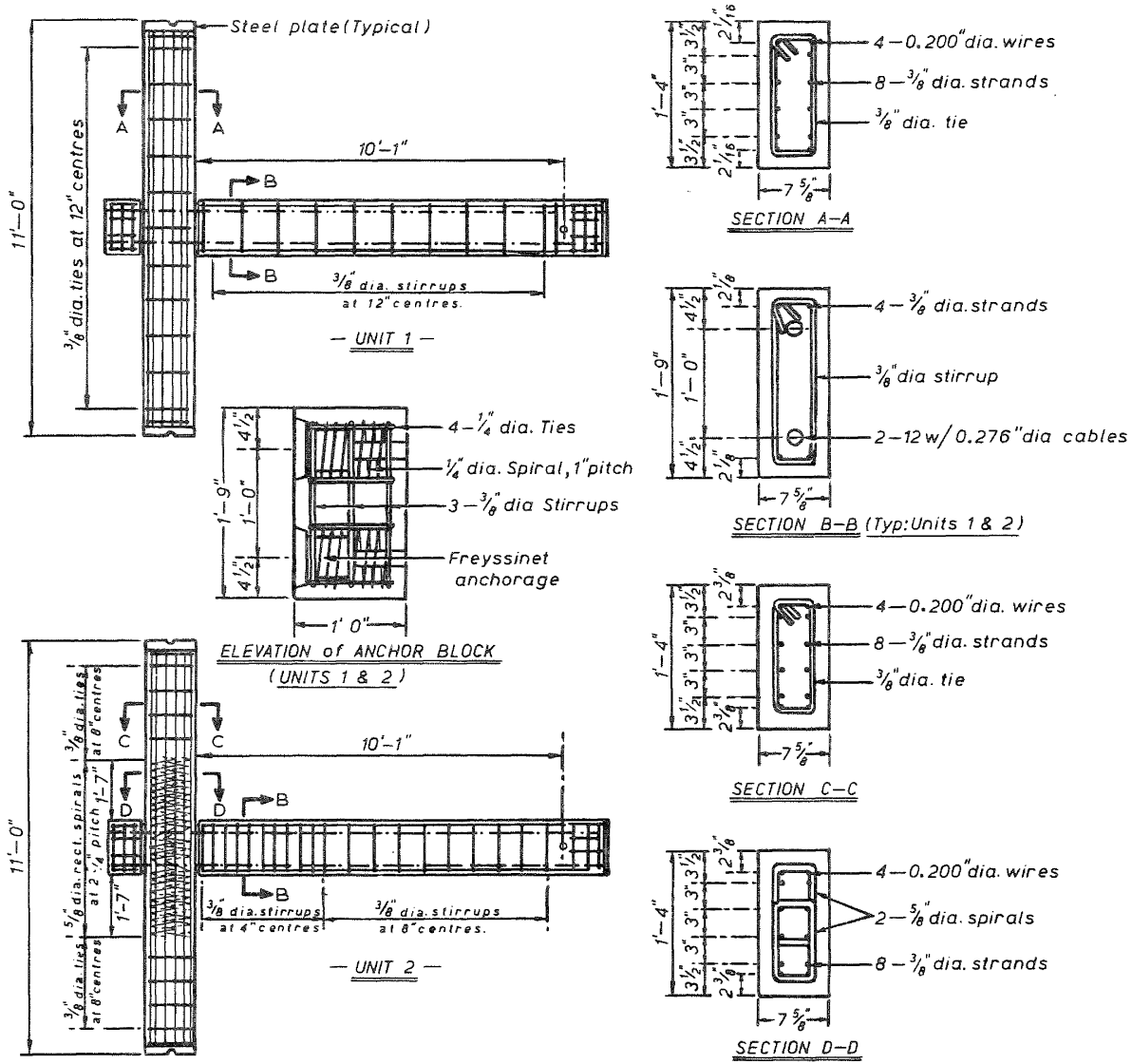

Fig. 20. Details of Units 1 and 2.
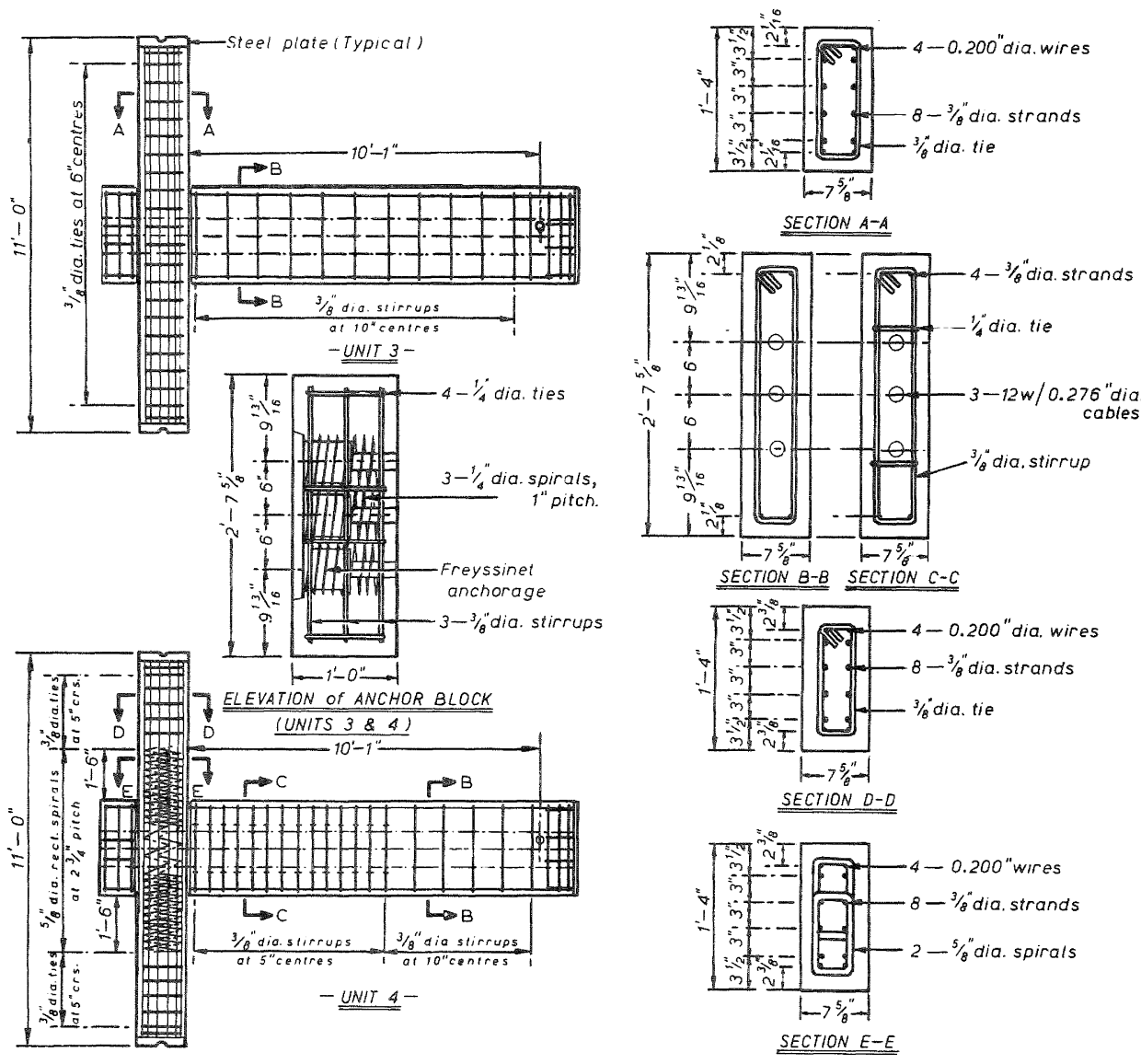

Fig. 21. Details of Units 3 and 4. 